\title{
Mannose/glucose-functionalized dendrimers to investigate the predictable tunability of multivalent interactions.
}

\author{
Mark L. Wolfenden and Mary J. Cloninger* \\ Department of Chemistry and Biochemistry and Center for Bioinspired Nanomaterials, Montana State \\ University, 108 Gaines Hall, Bozeman, MT 59717 (USA) \\ mcloninger@chemistry.montana.edu
}

\section{Supporting Information}

General methods. General reagents were purchased from Acros and Aldrich Chemical Companies. Concanavalin A (Con A) was purchased from Calbiochem. Methylene Chloride was purified on basic alumina, other solvents were used as received. 32-63 "40 micron flash" silica gel for flash column chromatography purification was purchased from Scientific Adsorbents Incorporated. The anomeric integrity of 2a-c was assessed by ${ }^{1} \mathrm{H}$ NMR (See Figures S2-S5). The $\square$ anomer is not detected when $\square$-mannose, $\square$-glucose, and $\square$-galactose substrates are used.

MALDI. Matrix assisted laser desorption ionization (MALDI) mass spectra were acquired using a Bruker Biflex-III time-of-flight mass spectrometer. Spectra of all functionalized dendrimers were obtained using a trans-3-indoleacrylic acid matrix with a matrix-analyte ratio of 3000:1 or 1000:1. Bovine serum albumin (MW 66,431 g/mol), Cytochrome C (MW 12,361 g/mol), and Trypsinogen (MW 23,982 g/mol) were used as external standards. An aliquot corresponding to 12-15 pmol of the analyte was deposited on the laser target. Positive ion mass spectra were acquired in linear mode and the ions were generated by using a nitrogen laser $(337 \mathrm{~nm})$ pulsed at $3 \mathrm{~Hz}$ with a pulse width of 3 nanoseconds. Ions were accelerated at 19-20,000 volts and amplified using a discrete dynode multiplier. Spectra (100 to 200) were summed into a LeCroy LSA1000 high-speed signal digitizer. All data processing was performed using Bruker XMass/XTOF V 5.0.2. Molecular mass data and polydispersities (PDI) of the broad peaks were calculated by using the Polymer Module included in the software package. $\mathrm{PDI}=\mathrm{M}_{\mathrm{N}} / \mathrm{M}_{\mathrm{W}}$, or the ratio of the number average molecular weight to the weighted average molecular weight. The peaks were analyzed using the continuous mode. In all the MALDI spectra, a second peak at half the molecular weight of the first peak is clearly visible; this is the $m / z$ peak where $z=2$.

To determine the number of carbohydrate residues of each type on the dendrimers, both the change in $\mathrm{M}_{\mathrm{W}}$ after each sequential addition and after deacylation were used. Starting $\mathrm{M}_{\mathrm{W}}$ for the PAMAM dendrimers was $13500 \mathrm{~g} / \mathrm{mol}, 25500 \mathrm{~g} / \mathrm{mol}$ and $50000 \mathrm{~g} / \mathrm{mol}$ for Generation 4, 5 and 6 , respectively. To calculate the number of different residues on each dendrimer, the MALDI-TOF MS weight average molecular weight $\left(\mathrm{M}_{\mathrm{w}}\right)$ change upon each addition was divided by the $\mathrm{M}_{\mathrm{w}}$ of the isothiocyanate-tethered carbohydrate $(2,507 \mathrm{~g} / \mathrm{mol})$ (\#A). The total average number of appended carbohydrate residues was determined by dividing the $\mathrm{M}_{\mathrm{w}}$ change upon deacetylation by 168 (the loss of 4 acetyl groups per sugar) (\#B). The \% of each carbohydrate residue was determined by $(\mathrm{A} / \square \mathrm{A}) * \mathrm{~B}(\# \mathrm{C})$. The values $\mathrm{C}$ and $\mathrm{A}$ were then averaged. An example, using 4c data: $(22900-13500) / 507=18.5(\mathrm{~A}) ;(34200-13500) / 507=40.8$ 
$(\square \mathrm{A}) ; 18.5 / 40.8 * 100=45.4 \% ;(34200-27700) / 168=38.7(\mathrm{~B}) ; 38.7 * 0.454=17.6(\mathrm{C})$; $(17.6+18.5) / 2=18.0$ (determined \# of mannose residues). Comparable (low) amounts of galactose were added in all cases, as evidenced by the constancy of the $\mathrm{M}_{\mathrm{W}}$ as determined by MALDI-TOF MS (see the characterization sections below for values).

NMR. ${ }^{1} \mathrm{H}$ NMR spectra were recorded on Bruker DPX $300(300 \mathrm{MHz})$ and Bruker DPX-500 $(500 \mathrm{MHz})$ spectrometers. Chemical shifts are reported in ppm from tetramethylsilane with the residual protic solvent resonance as the internal standard (chloroform: $\square 7.25 \mathrm{ppm}$; dimethyl sulfoxide: $\square 2.50 \mathrm{ppm}$ ). Data are reported as follows: chemical shift, multiplicity ( $=$ singlet, bs $=$ broad singlet, $\mathrm{d}=$ doublet, $\mathrm{t}=$ triplet, $\mathrm{q}=$ quartet, $\mathrm{p}=$ pentet, $\mathrm{m}=$ multiplet, app = apparent), integration, coupling constants (in $\mathrm{Hz}$ ) and assignments. ${ }^{13} \mathrm{C}$ NMR spectra were recorded on a Bruker DPX $500(125 \mathrm{MHz})$ spectrometer with complete proton decoupling. Chemical shifts are reported in ppm from tetramethylsilane with the solvent as the internal standard $\left(\mathrm{CDCl}_{3}: \square 77.0\right.$ ppm).

PAMAMs. PAMAM dendrimers were purchased from Dentritech and were used as received. For a discussion of the purity of PAMAMs as measured by MALDI-TOF MS, see: Woller, E. K.; Cloninger, M. J. Biomacromolecules 2001, 2, 1052-1054. We demonstrate using MALDITOF MS that the sample populations for the differentially loaded dendrimers do not overlap, so the lack of PAMAM homogeneity does not significantly influence our results. Errors from lack of PAMAM homogeneity cancel, since the degree of carbohydrate functionalization is uniform even when the nature of the sugar is varied. Carbohydrate functionalization as per the representative procedure below for formation of 4-6 produces a random distribution of carbohydrates. EPR/affinity chromatography experiments with TEMPO/mannose-functionalized PAMAMs indicate that random distributions on dynamic PAMAM frameworks effectively behave as uniformly functionalized compounds (Samuelson, L. E.; Sebby, K. B.; Walter, E. D.; Singel, D. J.; Cloninger, M. J. Org. Biomol. Chem., 2004, 2, 3075-3079).

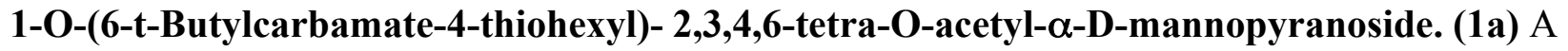

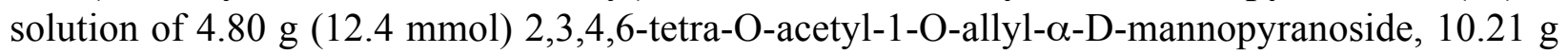
(57.6 mmol) 2-t-Butylcarbamate-ethanethiol and $1.0 \mathrm{~mL}(0.5 \mathrm{~g}, 1.9 \mathrm{mmol})$ 1,1 Di(tertbutylperoxy)cyclohexane (50\% w/v solution in mineral oil) in $100 \mathrm{~mL}$ of toluene was degassed with Argon and refluxed for $4 \mathrm{hrs}$. The solution was cooled and the solvent removed in vacuo. The remaining oily residue was then purified by silica gel column chromatography (1:1 hexanes:ethyl acetate) to give $4.41 \mathrm{~g}(7.81 \mathrm{mmol})$ of a yellow oil in $65 \%$ yield. ${ }^{1} \mathrm{H}$ NMR (300 $\left.\mathrm{MHz}, \mathrm{CDCl}_{3}\right) \square$ 5.21-5.30 (m, 3H, H2, H3, H4), 4.94 (bs, $\left.1 \mathrm{H}, \mathrm{CH}_{2} \mathrm{NHCOOt} \mathrm{Bu}\right), 4.80(\mathrm{~s}, 1 \mathrm{H}$, H1), 4.28 (dd, 1H, J = 12.1, 5.2Hz, H6a), $4.11(\mathrm{~m}, 1 \mathrm{H}, \boldsymbol{H 6 b}), 3.98(\mathrm{~m}, 1 \mathrm{H}, \boldsymbol{H 5}), 3.81$ (dt, J = 9.5, $\left.6.1 \mathrm{~Hz}, 1 \mathrm{H}, \mathrm{OCH}_{2} \mathrm{CH}_{2} \mathrm{CH}_{2} \mathrm{~S}\right), 3.53\left(\mathrm{dt}, \mathrm{J}=9.5,6.1 \mathrm{~Hz}, 1 \mathrm{H}, \mathrm{OCH}_{2} \mathrm{CH}_{2} \mathrm{CH}_{2} \mathrm{~S}\right), 3.30(\mathrm{~m}, 2 \mathrm{H}$, $\mathrm{CH}_{2} \mathrm{NHCOO} t \mathrm{Bu}$ ), 2.63 (app q, J = 12.3, 6.1 Hz, 4H, $\mathrm{CH}_{2} \mathrm{CH}_{2} \mathrm{SCH}_{2} \mathrm{CH}_{2}$ ), 2.13 (s, 3H), 2.11 (s, $3 \mathrm{H}), 2.10(\mathrm{~s}, 3 \mathrm{H}), 2.07(\mathrm{~s}, 3 \mathrm{H}), 1.88\left(\mathrm{~m}, 2 \mathrm{H}, \mathrm{OCH}_{2} \mathrm{CH}_{2} \mathrm{CH}_{2} \mathrm{SCH}_{2}\right), 1.45(\mathrm{~s}, 9 \mathrm{H}) \mathrm{ppm} .{ }^{13} \mathrm{C} \mathrm{NMR}$ $\left(125 \mathrm{MHz}, \mathrm{CDCl}_{3}\right) \square 170.46,169.90,169.74,169.58,155.70,97.49,79.19,69.52,69.01,68.53$, $66.37,66.14,62.43,39.77,32.13,29.00,28.29,28.22,20.88,20.73,20.61,20.55$ ppm. HRMS (electrospray) $m / z 588.2105\left(\mathrm{M}+\mathrm{Na}\right.$, calc. 588.2091 for $\mathrm{C}_{24} \mathrm{H}_{39} \mathrm{NO}_{12} \mathrm{SNa}$ )

1-O-(6-t-Butylcarbamate-4-thiohexyl)- 2,3,4,6-tetra-O-acetyl- $\square$-D-glucopyranoside. (1b) A solution of $0.4 \mathrm{~g}$ (1.0 mmol) 2,3,4,6-tetra-O-acetyl-1-O-allyl- $\square-\mathrm{D}$-glucopyranoside, $1.5 \mathrm{~g}(8.4$ 
mmol) 2-t-Butylcarbamate-ethanethiol and $0.2 \mathrm{~mL}(0.1 \mathrm{~g}, 0.38 \mathrm{mmol})$ 1,1 Di(tertbutylperoxy)cyclohexane (50\% w/v solution in mineral oil) in $20 \mathrm{~mL}$ of toluene was degassed with Argon and refluxed for $4 \mathrm{hrs}$. The solution was cooled and the solvent removed in vacuo. The remaining oily residue was then purified by silica gel column chromatography $(1: 1$ hexanes:ethyl acetate) to give $0.42 \mathrm{~g}(0.74 \mathrm{mmol})$ of a yellow oil in $74 \%$ yield. ${ }^{1} \mathrm{H}$ NMR (500 $\mathrm{MHz}_{\mathrm{CDCl}}$ ) $\square 5.39$ (app t, $\left.1 \mathrm{H}, \mathrm{J}=10.1 \mathrm{~Hz}, \boldsymbol{H 3}\right), 4.98\left(\mathrm{~m}, 3 \mathrm{H}, \boldsymbol{H} 4, \boldsymbol{H} \mathbf{1}, \mathrm{CH}_{2} \mathrm{NHCOO} t \mathrm{Bu}\right), 4.80$ $(\mathrm{dd}, 1 \mathrm{H}, \mathrm{J}=10.1,3.7 \mathrm{~Hz}, \boldsymbol{H 2}), 4.19(\mathrm{dd}, 1 \mathrm{H}, \mathrm{J}=12.3,3.9 \mathrm{~Hz}, \boldsymbol{H 6 a}), 4.03$ (dd, 1H, J = 12.3, 2.2 $\mathrm{Hz}, \boldsymbol{H 6} \boldsymbol{b}), 3.95(\mathrm{ddd}, 2 \mathrm{H}, \mathrm{J}=2.2,3.9,10.2 \mathrm{~Hz}, \boldsymbol{H 5}), 3.74(\mathrm{dt}, 1 \mathrm{H}, \mathrm{J}=9.9,6.1 \mathrm{~Hz}$ $\left.\mathrm{OCH}_{2} \mathrm{CH}_{2} \mathrm{CH}_{2} \mathrm{~S}\right), 3.45\left(\mathrm{dt}, 1 \mathrm{H}, \mathrm{J}=9.9,6.1 \mathrm{~Hz}, \mathrm{OCH}_{2} \mathrm{CH}_{2} \mathrm{CH}_{2} \mathrm{~S}\right), 3.24(\mathrm{~m}, 2 \mathrm{H}$, $\left.\mathrm{CH}_{2} \mathrm{NHCOO} t \mathrm{Bu}\right), 2.57\left(\mathrm{~m}, 4 \mathrm{H}, \mathrm{CH}_{2} \mathrm{CH}_{2} \mathrm{SCH}_{2} \mathrm{CH}_{2}\right), 2.03(\mathrm{~s}, 3 \mathrm{H}), 2.00(\mathrm{~s}, 3 \mathrm{H}), 1.96(\mathrm{~s}, 3 \mathrm{H}), 1.94$ $(\mathrm{s}, 3 \mathrm{H}), 1.83$ (app p, 2H, J = 6.5 Hz, $\left.\mathrm{OCH}_{2} \mathrm{CH}_{2} \mathrm{CH}_{2} \mathrm{SCH}_{2}\right), 1.37$ (s, 9H) ppm. ${ }^{13} \mathrm{C}$ NMR $(125$ $\left.\mathrm{MHz}, \mathrm{CDCl}_{3}\right) \square 170.53,170.02$ (2), 169.49, 155.72, 95.77, 79.33, 70.78, 70.13, 68.58, 67.28, $66.57,61.89,39.77,32.08,29.01,28.32,28.09,20.64,20.59,20.52$ ppm. HRMS (electrospray) $m / z 588.2091\left(\mathrm{M}+\mathrm{Na}\right.$, calc. 588.2091 for $\left.\mathrm{C}_{24} \mathrm{H}_{39} \mathrm{NO}_{12} \mathrm{SNa}\right)$.

1-O-(6-t-Butylcarbamate-4-thiohexyl)- 2,3,4,6-tetra-O-acetyl- $-\mathrm{D}$-galactopyranoside. (1c) A solution of $3.90 \mathrm{~g}$ (10.1 mmol) 2,3,4,6-tetra-O-acetyl-1-O-allyl- $\square$-D-galactopyranoside, $11.9 \mathrm{~g}$ (67.2 mmol) 2-t-Butylcarbamate-ethanethiol and $1.0 \mathrm{~mL}(0.5 \mathrm{~g}, 1.9 \mathrm{mmol}) 1,1 \mathrm{Di}($ tertbutylperoxy)cyclohexane $(50 \% \mathrm{w} / \mathrm{v}$ solution in mineral oil) in $100 \mathrm{~mL}$ of toluene was degassed with Argon and refluxed for $4 \mathrm{hrs}$. The solution was cooled and the solvent removed in vacuo. The remaining oily residue was then purified by silica gel column chromatography $(1: 1$ hexanes:ethyl acetate) to give $4.3 \mathrm{~g}(7.61 \mathrm{mmol})$ of a yellow oil in $76 \%$ yield. ${ }^{1} \mathrm{H}$ NMR (300 $\left.\mathrm{MHz} \mathrm{CDCl}_{3}\right) \square 5.44(\operatorname{app~d}, 1 \mathrm{H}, \mathrm{J}=3.0 \mathrm{~Hz}, \boldsymbol{H 4}), 5.31(\mathrm{dd}, 1 \mathrm{H}, \mathrm{J}=3.0,9.6 \mathrm{~Hz}, \boldsymbol{H 3}), 5.10(\mathrm{~m}$, $2 \mathrm{H}, \boldsymbol{H 1}, \boldsymbol{H 2}), 4.91$ (bs, 1H, $\left.\mathrm{CH}_{2} \mathrm{NHCOO} t \mathrm{Bu}\right), 4.20$ (ap t, $\left.1 \mathrm{H}, \mathrm{J}=6.5 \mathrm{~Hz}, \boldsymbol{H 5}\right), 4.08$ (d, 2H, J = $6.5 \mathrm{~Hz}, \boldsymbol{H 6}$ ), $3.76\left(\mathrm{dt}, \mathrm{J}=6.0,12.0 \mathrm{~Hz}, 1 \mathrm{H}, \mathrm{OCH}_{2} \mathrm{CH}_{2} \mathrm{CH}_{2} \mathrm{~S}\right), 3.50$ (dt, J = 6.0, $12.0 \mathrm{~Hz}, 1 \mathrm{H}$, $\left.\mathrm{OCH}_{2} \mathrm{CH}_{2} \mathrm{CH}_{2} \mathrm{~S}\right), 3.29\left(\mathrm{~m}, 2 \mathrm{H}, \mathrm{CH}_{2} \mathrm{NHCOO} t \mathrm{Bu}\right), 2.60(\operatorname{app} \mathrm{q}, \mathrm{J}=6.3,12.3 \mathrm{~Hz}, 4 \mathrm{H}$, $\left.\mathrm{CH}_{2} \mathrm{CH}_{2} \mathrm{SCH}_{2} \mathrm{CH}_{2}\right), 2.13(\mathrm{~s}, 3 \mathrm{H}), 2.11(\mathrm{~s}, 3 \mathrm{H}), 2.10(\mathrm{~s}, 3 \mathrm{H}), 2.07$ (s, 3H), 1.88 (app p, J = 6.6 Hz, $\left.2 \mathrm{H}, \mathrm{OCH}_{2} \mathrm{CH}_{2} \mathrm{CH}_{2} \mathrm{SCH}_{2}\right), 1.45$ (s, 9H) ppm. ${ }^{13} \mathrm{C} \mathrm{NMR}\left(125 \mathrm{MHz}, \mathrm{CDCl}_{3}\right) \square$ 170.60, 170.54, $170.38,170.19,155.95,96.52,79.64,68.42$, 68.32, 67.83, 66.94, 66.58, 61.95, 40.01, 32.43, 29.36, 28.60, 28.46, 20.96, 20.90, 20.84, $20.82 \mathrm{ppm}$. HRMS (electrospray) $\mathrm{m} / \mathrm{z} 588.2094$ $\left(\mathrm{M}+\mathrm{Na}\right.$, calc. 588.2091 for $\left.\mathrm{C}_{24} \mathrm{H}_{39} \mathrm{NO}_{12} \mathrm{SNa}\right)$.

1-O-(6-isothiocyanato-4-thiohexyl)- 2,3,4,6-tetra-O-acetyl - $\square$-D-mannopyranoside. (2a) 1.1 $\mathrm{g}(9.6 \mathrm{mmol})$ of trifluoroacetic acid was added to a solution of $1.0 \mathrm{~g}(1.8 \mathrm{mmol})$ of $1 \mathrm{a}$ in $10 \mathrm{~mL}$ of methylene chloride at $0^{\circ} \mathrm{C}$ and let stir for $12 \mathrm{hrs}$. Solvent was removed in vacuo and $10 \mathrm{~mL}$ water added to the residue. The $\mathrm{pH}$ of the solution was then adjusted to $\sim 12$ with a solution of $\mathrm{K}_{2} \mathrm{CO}_{3}$ (sat.) and extracted with methylene chloride $(3 \times 10 \mathrm{~mL})$. The organic layers where combined and washed with brine $(10 \mathrm{~mL})$ and dried with sodium sulfate. The extract was filtered and the solvent removed. The resulting oily material was then dissolved in dry methylene chloride $(10 \mathrm{~mL})$ with $0.45 \mathrm{~g}(4.5 \mathrm{mmol})$ of triethylamine. This was then added via syringe pump to a solution of $0.2 \mathrm{~mL}(0.3 \mathrm{~g}, 2.6 \mathrm{mmol})$ thiophosgene in $30 \mathrm{~mL}$ of dry methylene chloride at $0^{\circ} \mathrm{C}$ over $1 \mathrm{hr}$ and let stir for a further $2 \mathrm{hr}$. Water $(30 \mathrm{~mL})$ was added and extraction performed with methylene chloride $(3 \times 20 \mathrm{~mL})$, the organic layers were then combined and dried over sodium sulfate. The extract was filtered and solvent removed in vacuo to yield a reddish oily material. The product was purified via column chromatography on silica gel (2:1 ethyl acetate:hexanes) leaving $0.50 \mathrm{~g}(0.99 \mathrm{mmol})$ of a yellowish oil in a $55 \%$ yield. ${ }^{1} \mathrm{H} \mathrm{NMR}$ 
$\left(300 \mathrm{MHz}, \mathrm{CDCl}_{3}\right) \square 5.21-5.30(\mathrm{~m}, 1 \mathrm{H}, \boldsymbol{H} \mathbf{2}, \boldsymbol{H} 3, \boldsymbol{H 4}), 4.80(\mathrm{~s}, 1 \mathrm{H}, \boldsymbol{H 1}), 4.28(\mathrm{dd}, 1 \mathrm{H}, \mathrm{J}=12.3$, 6.9Hz, H6a ), 4.11 (app d, 1H, J = 12.3Hz, H6b), 3.98 (m, 1H, H5), 3.81 (dt, J = 6.1, $10.0 \mathrm{~Hz}$, $1 \mathrm{H}, \mathrm{OCH}_{2} \mathrm{CH}_{2} \mathrm{CH}_{2} \mathrm{~S}$ ), 3.69 (t, 2H, J = 6.8 Hz, SCH $\mathrm{CH}_{2} \mathrm{NCS}$ ), 3.53 (dt, 1H, J = 6.1, $10.0 \mathrm{~Hz}$, $\left.\mathrm{OCH}_{2} \mathrm{CH}_{2} \mathrm{CH}_{2} \mathrm{~S}\right), 2.81\left(\mathrm{t}, 2 \mathrm{H}, \mathrm{J}=6.8 \mathrm{~Hz}, \mathrm{SCH}_{2} \mathrm{CH}_{2} \mathrm{NCS}\right), 2.66(\mathrm{t}, 2 \mathrm{H}, \mathrm{J}=7.0 \mathrm{~Hz}$, $\left.\mathrm{OCH}_{2} \mathrm{CH}_{2} \mathrm{CH}_{2} \mathrm{~S}\right), 2.13(\mathrm{~s}, 3 \mathrm{H}), 2.11(\mathrm{~s}, 3 \mathrm{H}), 2.10(\mathrm{~s}, 3 \mathrm{H}), 2.07(\mathrm{~s}, 3 \mathrm{H}), 1.88(\mathrm{~m}, 2 \mathrm{H}$, $\left.\mathrm{OCH}_{2} \mathrm{CH}_{2} \mathrm{CH}_{2} \mathrm{SCH}_{2}\right)$ ppm. ${ }^{13} \mathrm{C}$ NMR $\left(125 \mathrm{MHz}, \mathrm{CDCl}_{3}\right) \square 170.49,169.95,169.81,169.61$, $132.39,97.53,69.49,69.01,68.59,66.25,66.11,62.45,45.17,32.25,29.05,28.88,20.79,20.69$, 20.63, 20.60 ppm. HRMS (electrospray) $\mathrm{m} / \mathrm{z} 530.1112$ (M+Na, calc. 530.1131 for $\mathrm{C}_{20} \mathrm{H}_{29} \mathrm{NO}_{10} \mathrm{~S}_{2} \mathrm{Na}$ ).

1-O-(6-isothiocyanato-4-thiohexyl)- 2,3,4,6-tetra-O-acetyl - $\square$-D-glucopyranoside. (2b) $0.5 \mathrm{~g}$ (4 mmol) of trifluoroacetic acid was added to a solution of $0.42 \mathrm{~g}(0.74 \mathrm{mmol})$ of $1 \mathrm{~b}$ in $5 \mathrm{~mL}$ of methylene chloride at $0^{\circ} \mathrm{C}$ and let stir for $12 \mathrm{hrs}$. Solvent was removed in vacuo and $5 \mathrm{~mL}$ water added to the residue. The $\mathrm{pH}$ of the solution was then adjusted to $\sim 12$ with a solution of $\mathrm{K}_{2} \mathrm{CO}_{3}$ (sat.) and extracted with methylene chloride $(3 \times 10 \mathrm{~mL})$. The organic layers where combined and washed with brine $(10 \mathrm{~mL})$ and dried with sodium sulfate. The extract was filtered and the solvent removed in vacuo. The resulting oily material was then dissolved in dry methylene chloride $(10 \mathrm{~mL})$ with $0.2 \mathrm{~g}(2 \mathrm{mmol})$ of triethylamine. This was then added via syringe pump to a solution of $0.13 \mathrm{~g}(1 \mathrm{mmol})$ thiophosgene in $10 \mathrm{~mL}$ of dry methylene chloride at $0^{\circ} \mathrm{C}$ over $1 \mathrm{hr}$. this was then let stir for $2 \mathrm{hr}$. Water $(10 \mathrm{~mL})$ was added and extracted with methylene chloride (3 $\mathrm{x} 10 \mathrm{~mL}$ ), the organic layers were then combined and dried over sodium sulfate. The extract was filtered and solvent removed in vacuo to yield a reddish oily material. The product was purified via column chromatography on silica gel (2:1 ethyl acetate:hexanes) leaving $0.3 \mathrm{~g}(0.59 \mathrm{mmol})$ of a yellowish oil in an 80\% yield. ${ }^{1} \mathrm{H}$ NMR $\left(500 \mathrm{MHz}, \mathrm{CDCl}_{3}\right) \square 5.41$ (app t, $1 \mathrm{H}, \mathrm{J}=10.0 \mathrm{~Hz}$, H3), 5.01 (m, 2H, H4, H1 ), 4.82 (dd, 1H, J = 10.0, 3.7 Hz, H2), 4.21 (dd, 1H, J = 12.3, 4.5 Hz, H6a), 4.05 (dd, 1H, J = 12.3, 2.2 Hz, H6b), 3.95 (ddd, 1H, J = 10.2, 4.5, $2.2 \mathrm{~Hz}, \boldsymbol{H 5}$ ), 3.77 (dt, $\left.1 \mathrm{H}, \mathrm{J}=9.9,6.0 \mathrm{~Hz} \mathrm{OCH}_{2} \mathrm{CH}_{2} \mathrm{CH}_{2} \mathrm{~S}\right), 3.66\left(\mathrm{t}, 2 \mathrm{H}, \mathrm{J}=6.7 \mathrm{~Hz}, \mathrm{CH}_{2} \mathrm{NCS}\right), 3.48(\mathrm{dt}, 1 \mathrm{H}, \mathrm{J}=9.9,6.0$ $\left.\mathrm{Hz}, \mathrm{OCH}_{2} \mathrm{CH}_{2} \mathrm{CH}_{2} \mathrm{~S}\right), 2.78\left(\mathrm{t}, 2 \mathrm{H}, \mathrm{J}=6.7 \mathrm{~Hz}, \mathrm{SCH}_{2} \mathrm{CH}_{2} \mathrm{NCS}\right), 2.65(\mathrm{t}, 2 \mathrm{H}, \mathrm{J}=7.0 \mathrm{~Hz}$, $\left.\mathrm{CH}_{2} \mathrm{CH}_{2} \mathrm{~S}\right), 2.05(\mathrm{~s}, 3 \mathrm{H}), 2.02(\mathrm{~s}, 3 \mathrm{H}), 1.99(\mathrm{~s}, 3 \mathrm{H}), 1.97(\mathrm{~s}, 3 \mathrm{H}), 1.87$ (app p, 2H, J = 6.5 Hz, $\left.\mathrm{OCH}_{2} \mathrm{CH}_{2} \mathrm{CH}_{2} \mathrm{SCH}_{2}\right), 1.37$ (s, 9H) ppm. ${ }^{13} \mathrm{C} \mathrm{NMR}\left(125 \mathrm{MHz}, \mathrm{CDCl}_{3}\right) \square 170.75,170.27,170.22$, 169.71, 132.85, 96.02, 70.99, 70.28, 68.78, 67.81, 67.55, 66.64, 62.11, 45.79, 45.40, 32.39, 29.83, 29.30, 28.98, 20.89, 20.84, 20.77 ppm. HRMS (electrospray) $m / z ~ 530.1138$ (M+Na, calc. 530.1131 for $\mathrm{C}_{20} \mathrm{H}_{29} \mathrm{NO}_{10} \mathrm{~S}_{2} \mathrm{Na}$ ).

1-O-(6-isothiocyanato-4-thiohexyl)- 2,3,4,6-tetra-O-acetyl - $\square$-D-galactopyranoside. (2c) 0.5 $\mathrm{g}(4 \mathrm{mmol})$ of trifluoroacetic acid was added to a solution of $0.42 \mathrm{~g}(0.74 \mathrm{mmol})$ of $1 \mathrm{c}$ in $10 \mathrm{~mL}$ of methylene chloride at $0^{\circ} \mathrm{C}$ and let stir for $12 \mathrm{hrs}$. Solvent was removed in vacuo and $10 \mathrm{~mL}$ water added to the residue. The $\mathrm{pH}$ of the solution was then adjusted to $\sim 12$ with a solution of $\mathrm{K}_{2} \mathrm{CO}_{3}$ (sat.) and extracted with methylene chloride $(3 \times 10 \mathrm{~mL})$. The organic layers where combined and washed with brine $(10 \mathrm{~mL})$ and dried with sodium sulfate. The extract was filtered and the solvent removed in vacuo. The resulting oily material was then dissolved in dry methylene chloride $(10 \mathrm{~mL})$ with $0.18 \mathrm{~g}(2 \mathrm{mmol})$ of triethylamine. This was then added via syringe pump to a solution of $0.12 \mathrm{~g}(1 \mathrm{mmol})$ thiophosgene in $20 \mathrm{~mL}$ of dry methylene chloride at $0^{\circ} \mathrm{C}$ over $1 \mathrm{hr}$. The reaction was then let stir for $2 \mathrm{hr}$. Water $(30 \mathrm{~mL})$ was added and extracted with methylene chloride $(3 \times 20 \mathrm{~mL})$, the organic layers were then combined and dried over sodium sulfate. The extract was filtered and solvent removed in vacuo to yield a reddish oily 
material. The product was purified via column chromatography on silica gel (2:1 ethyl acetate:hexanes) leaving $0.28 \mathrm{~g}(0.55 \mathrm{mmol})$ of a yellowish oil in a $75 \%$ yield. ${ }^{1} \mathrm{H}$ NMR $(300$ $\left.\mathrm{MHz}_{\mathrm{CDCl}}\right)_{3} \square 5.43(\mathrm{~d}, 1 \mathrm{H}, \mathrm{J}=2.3 \mathrm{~Hz}, \boldsymbol{H} 4), 5.31(\mathrm{dd}, 1 \mathrm{H}, \mathrm{J}=10.1,2.3 \mathrm{~Hz}, \boldsymbol{H 3}), 5.11(\mathrm{~m}, 2 \mathrm{H}$, $\boldsymbol{H 1}, \boldsymbol{H 2}), 4.21(\mathrm{t}, 1 \mathrm{H}, \mathrm{J}=6.4 \mathrm{~Hz}, \boldsymbol{H 5}), 4.10(\mathrm{~m}, 2 \mathrm{H}, \boldsymbol{H 6}), 3.79\left(\mathrm{~m}, 1 \mathrm{H}, \mathrm{OCH}_{2} \mathrm{CH}_{2} \mathrm{CH}_{2} \mathrm{~S}\right), 3.70(\mathrm{t}$, $\left.2 \mathrm{H}, \mathrm{J}=6.8 \mathrm{~Hz}, \mathrm{SCH}_{2} \mathrm{CH}_{2} \mathrm{NCS}\right), 3.52\left(\mathrm{~m}, 1 \mathrm{H} \mathrm{OCH}_{2} \mathrm{CH}_{2} \mathrm{CH}_{2} \mathrm{~S}\right), 2.80(\mathrm{t}, 2 \mathrm{H}, \mathrm{J}=6.8 \mathrm{~Hz}$, $\left.\mathrm{SCH}_{2} \mathrm{CH}_{2} \mathrm{NCS}\right), 2.66\left(\mathrm{t}, 2 \mathrm{H}, \mathrm{J}=6.7 \mathrm{~Hz}, \mathrm{OCH}_{2} \mathrm{CH}_{2} \mathrm{CH}_{2} \mathrm{~S}\right), 2.11(\mathrm{~s}, 3 \mathrm{H}), 2.06(\mathrm{~s}, 3 \mathrm{H}), 2.03$ (s, $3 \mathrm{H}), 1.98(\mathrm{~s}, 3 \mathrm{H}), 1.88\left(\mathrm{~m}, 2 \mathrm{H}, \mathrm{OCH}_{2} \mathrm{CH}_{2} \mathrm{CH}_{2} \mathrm{SCH}_{2}\right)$ ppm. ${ }^{13} \mathrm{C} \mathrm{NMR}\left(125 \mathrm{MHz}, \mathrm{CDCl}_{3}\right) \square$ $170.47,170.39,170.27,170.09,132.71,96.44,68.27,68.17,67.67,66.70,66.48,61.82,45.36$, $32.34,29.33,29.02,20.89,20.81,20.74,20.71 \mathrm{ppm}$. HRMS (electrospray) $\mathrm{m} / z$ 530.1130 $\left(\mathrm{M}+\mathrm{Na}\right.$, calc. 530.1131 for $\mathrm{C}_{20} \mathrm{H}_{29} \mathrm{NO}_{10} \mathrm{~S}_{2} \mathrm{Na}$ ).

Representative procedure for the synthesis of heterogeneously functionalized PAMAMbased thiourea-linked 1-O-(6-thiourea-4-thiohexyl)- 2,3,4,6-tetra-O-acetyl - $\square-D-$ galactopyranoside, 1-O-(6- thiourea-4-thiohexyl)- 2,3,4,6-tetra-O-acetyl - $\square-D$ glucopyranoside, 1-O-(6- thiourea-4-thiohexyl)- 2,3,4,6-tetra-O-acetyl - $-D$ mannopyranoside. (4-6) An aqueous solution of amine terminated Starburst G(4)-PAMAM dendrimer $(2.478 \mathrm{~g}$ of a $17 \% \mathrm{w} / \mathrm{w}$ solution in water, $421.2 \mathrm{mg}, 31.2 \square \mathrm{mol})$ was lyophilized to leave a foamy residue. $7.02 \mathrm{~mL}$ of DMSO was then added to this residue to give a $60 \mathrm{mg} / \mathrm{mL}$ solution. $0.047 \mathrm{~mL}$ of a $300 \mathrm{mM}$ solution of 1-O-(6-isothiocyanato-4-thiohexyl)- 2,3,4,6-tetra-Oacetyl - $\square$-D-mannopyranoside (2a, $14.1 \square \mathrm{mol}, 6.84 \mathrm{mg}$ ) in DMSO was added to $0.5 \mathrm{~mL}$ of a 60 $\mathrm{mg} / \mathrm{mL} \mathrm{G}(4)$ PAMAM dendrimer $(30 \mathrm{mg}, 4.40$ Dmol) solution. The reaction was stirred for 48 hrs at which point a $75 \square \mathrm{L}$ aliquot was removed for MALDI-TOF analysis. After MALI-TOF analysis indicated reaction completion $0.17 \mathrm{~mL}$ of a $300 \mathrm{mM}$ solution of 1-O-(6-isothiocyanato4-thiohexyl)- 2,3,4,6-tetra-O-acetyl - $\square$-D-glucopyranoside (2b, $49.4 \square \mathrm{mol}, 25.1 \mathrm{mg}$ ) was added. The solution was then stirred for $48 \mathrm{hrs}$. At this time a $75 \square \mathrm{L}$ aliquot was removed for analysis. After MALDI-TOF analysis indicated reaction completion, $0.19 \mathrm{~mL}$ of a $300 \mathrm{mM}$ solution of 1O-(6-isothiocyanato-4-thiohexyl)- 2,3,4,6-tetra-O-acetyl - $\square$-D-galactopyranoside (2c, $56.9 \square \mathrm{mol}$, $28.8 \mathrm{mg}$ ) was added and let stir for $48 \mathrm{hrs}$, when a $75 \square \mathrm{L}$ aliquot was removed for analysis. According to MALDI-TOF analysis the addition of $\mathbf{2 c}$ did not go to completion, so an additional spacer was added. $47.1 \mathrm{mg}$ (30 $\square \mathrm{mol})$ of isothiocyanto-ethoxyethanol 3 in DMSO was added an let stir at room temperature for 2 days. Again MALDI-TOF analysis indicated no further addition. This step was repeated with mild warming (up to $40{ }^{\circ} \mathrm{C}$ ) and vigorous stirring. MALDITOF analysis again indicated no further addition, hence the product was taken forward. 
Table S1. Amounts of compounds that were used for the experimental procedure above.

\begin{tabular}{|l|l|l|l|l|l|}
\hline $\begin{array}{l}\text { Compound } \\
\#\end{array}$ & $\begin{array}{l}\text { PAMAM } \\
(\square \mathrm{mol})\end{array}$ & $\begin{array}{l}\text { Mannose } \\
(\square \mathrm{mol})\end{array}$ & $\begin{array}{l}\text { Glucose } \\
(\square \mathrm{mol})\end{array}$ & $\begin{array}{l}\text { Galactose } \\
(\square \mathrm{mol})\end{array}$ & $\begin{array}{l}\text { Ethoxy } \\
\text { ethanol } \\
(\square \mathrm{mol})\end{array}$ \\
\hline 4a & 2.2 & 71.1 & 0 & 57.0 & 30.0 \\
\hline 4b & 2.2 & 56.9 & 12.6 & 57.0 & 30.0 \\
\hline 4c & 2.2 & 35.6 & 32.4 & 57.0 & 30.0 \\
\hline $\mathbf{4 d}$ & 2.2 & 14.2 & 51.0 & 57.0 & 30.0 \\
\hline $\mathbf{4 e}$ & 1.5 & 0 & 47.3 & 49.3 & 30.0 \\
\hline $\mathbf{5 a}$ & 1.2 & 58.8 & 0 & 45.0 & 30.0 \\
\hline $\mathbf{5 b}$ & 1.2 & 47.1 & 10.5 & 45.0 & 30.0 \\
\hline $\mathbf{5 c}$ & 1.2 & 11.8 & 42.6 & 45.0 & 30.0 \\
\hline $\mathbf{5 d}$ & 0.7 & 0 & 39.5 & 49.3 & 30.0 \\
\hline $\mathbf{6 a}$ & 0.6 & 50.2 & 0 & 42.0 & 30.0 \\
\hline $\mathbf{6 b}$ & 0.6 & 25.1 & 22.5 & 42.0 & 30.0 \\
\hline $\mathbf{6 c}$ & 0.6 & 10.0 & 36.3 & 42.0 & 30.0 \\
\hline $\mathbf{6 d}$ & 0.4 & 0 & 33.5 & 49.3 & 30.0 \\
\hline
\end{tabular}

4a: ${ }^{1} \mathrm{H}$ NMR (500 MHz, $d_{6}$-DMSO) $\square 7.97$ (bs, 1H, amide NH's), 7.90 (bs, 0.4H, amide NH's), 7.83 (bs, 0.5H, amide NH's), 7.77 (bs, 0.8H, amide NH's), 7.51 (bs, $\left.1.8 \mathrm{H}, \mathrm{CH}_{2} \mathrm{NHC}(\mathrm{S}) \mathrm{NHCH}_{2}\right)$ $5.32(\mathrm{~m}, 0.7 \mathrm{H}), 5.17(\mathrm{~m}, 0.8 \mathrm{H}), 5.07(\mathrm{~m}, 1.6 \mathrm{H}), 5.02(\mathrm{~m}, 0.8 \mathrm{H}), 4.92(\mathrm{~m}, 1 \mathrm{H}), 4.84(\mathrm{~m}, 0.5 \mathrm{H})$, $4.21(\mathrm{~m}, 0.7 \mathrm{H}), 4.10(\mathrm{~m}, 0.9 \mathrm{H}), 4.00(\mathrm{~m}, 2.3 \mathrm{H}), 3.90(\mathrm{~m}, 0.7), 3.80(\mathrm{t}, 0.8 \mathrm{H}, \mathrm{J}=6.5 \mathrm{~Hz}), 3.68(\mathrm{~m}$, $1.8 \mathrm{H}), 3.50(\mathrm{~m}, 3.2 \mathrm{H}), 3.14(\mathrm{bs}, 2.5 \mathrm{H}), 3.04(\mathrm{bs}, 3.9 \mathrm{H}), 2.81(\mathrm{t}, 0.5 \mathrm{H} \mathrm{J}=6.5 \mathrm{~Hz}), 2.56-2.64(\mathrm{~m}$, $11.4 \mathrm{H}), 2.17(\mathrm{bs}, 4.8 \mathrm{H}), 2.08(\mathrm{~s}, 3.2 \mathrm{H}), 2.07(\mathrm{~s}, 3 \mathrm{H}), 2.00(\mathrm{~m}, 9 \mathrm{H}), 1.90(\mathrm{~s}, 3.5 \mathrm{H}) 1.79(\mathrm{~m}, 3.5 \mathrm{H})$ ppm. MALDI-TOF (pos) m/z 34400 .

4b: ${ }^{1} \mathrm{H}$ NMR (500 MHz, $d_{6}$-DMSO) $\square 7.97$ (bs, 1H, amide NH's), 7.90 (bs, 0.5H, amide NH's), 7.83 (bs, $0.5 \mathrm{H}$, amide NH's), 7.77 (bs, $0.8 \mathrm{H}$, amide NH's), 7.51 (bs, $\left.1.8 \mathrm{H}, \mathrm{CH}_{2} \mathrm{NHC}(\mathrm{S}) \mathrm{NHCH}{ }_{2}\right)$ 5.32(m, 0.8H), $5.17(\mathrm{~m}, 0.8 \mathrm{H}), 5.07(\mathrm{~m}, 1.1 \mathrm{H}), 5.02(\mathrm{~m}, 0.8 \mathrm{H}), 4.99(\mathrm{~m}, 0.17 \mathrm{H}), 4.93(\mathrm{~m}, 0.9 \mathrm{H})$, $4.84(\mathrm{~m}, 0.5 \mathrm{H}), 4.21(\mathrm{~m}, 0.8 \mathrm{H}), 4.10(\mathrm{~m}, 0.8 \mathrm{H}), 4.00(\mathrm{~m}, 2.4 \mathrm{H}), 3.80(\mathrm{t}, 1.1 \mathrm{H}, \mathrm{J}=6.5 \mathrm{~Hz}), 3.68$ $(\mathrm{m}, 1.6 \mathrm{H}), 3.50(\mathrm{~m}, 3.8 \mathrm{H}), 3.14(\mathrm{bs}, 2.5 \mathrm{H}), 3.04(\mathrm{bs}, 3.9 \mathrm{H}), 2.81(\mathrm{t}, 1 \mathrm{H} \mathrm{J}=6.5 \mathrm{~Hz}), 2.56-2.64(\mathrm{~m}$, 13H), 2.17 (bs, 5H), 2.08 (s, 4H), 2.07 (s, 2H), 2.00 (s, 3.5H), 1.99 (s, 3H) 1.98 (s, 3H), 1.97 (s, 3H), 1.90 (s, 3.5H) 1.79 (m, 4H) ppm. MALDI-TOF (pos) m/z 33800.

4c: ${ }^{1} \mathrm{H}$ NMR (500 MHz, $d_{6}$-DMSO) $\square 7.97$ (bs, 1H, amide NH's), 7.83 (bs, 1H, amide NH's), 7.77 (bs, $1 \mathrm{H}$, amide NH's), 7.51 (bs, $\left.1.8 \mathrm{H}, \mathrm{CH}_{2} \mathrm{NHC}(\mathrm{S}) \mathrm{NHCH}_{2}\right) 5.32(\mathrm{~m}, 0.8 \mathrm{H}), 5.25(\mathrm{~m}, 0.5 \mathrm{H})$, $5.17(\mathrm{~m}, 0.8 \mathrm{H}), 5.07(\mathrm{~m}, 0.5 \mathrm{H}), 5.02(\mathrm{~m}, 0.8 \mathrm{H}), 4.99(\mathrm{~m}, 0.5 \mathrm{H}), 4.92(\mathrm{~m}, 1.3 \mathrm{H}), 4.84(\mathrm{~m}, 0.3 \mathrm{H})$, $4.75(\mathrm{~m}, 0.7 \mathrm{H}), 4.21(\mathrm{~m}, 0.8 \mathrm{H}), 4.09(\mathrm{~m}, 0.8 \mathrm{H}), 4.00(\mathrm{~m}, 2.6 \mathrm{H}), 3.80(\mathrm{t}, 1.1 \mathrm{H}, \mathrm{J}=6.5 \mathrm{~Hz}), 3.68$ $(\mathrm{m}, 2 \mathrm{H}), 3.50(\mathrm{~m}, 4 \mathrm{H}), 3.13(\mathrm{bs}, 2.5 \mathrm{H}), 3.04(\mathrm{bs}, 4.7 \mathrm{H}), 2.81(\mathrm{t}, 1 \mathrm{H}, \mathrm{J}=6.5 \mathrm{~Hz}), 2.56-2.64(\mathrm{~m}$, 17H), $2.17(\mathrm{bs}, 6.5 \mathrm{H}), 2.08(\mathrm{~s}, 3.7 \mathrm{H}), 2.00(\mathrm{~s}, 3 \mathrm{H}), 1.99(\mathrm{~s}, 2 \mathrm{H}), 1.98(\mathrm{~s}, 3 \mathrm{H}), 1.97(\mathrm{~s}, 3 \mathrm{H}) 1.96(\mathrm{~s}$, 2H), 1.90 (s, 3H) 1.79 (m, 4.7H) ppm. MALDI-TOF (pos) m/z 34200.

4d: ${ }^{1} \mathrm{H}$ NMR (500 MHz, $d_{6}$-DMSO) $\square 7.97$ (bs, 1H, amide NH's), 7.78 (bs, 0.8H, amide NH's), 7.51 (bs, 2H, $\left.\mathrm{CH}_{2} \mathrm{NHC}(\mathrm{S}) \mathrm{NHCH}_{2}\right) 5.32(\mathrm{~m}, 0.9 \mathrm{H}), 5.26(\mathrm{~m}, 1 \mathrm{H}), 5.17(\mathrm{~m}, 1 \mathrm{H}), 5.02(\mathrm{~m}, 0.8 \mathrm{H})$, $4.99(\mathrm{~m}, 0.8 \mathrm{H}) 4.92(\mathrm{~m}, 1.6 \mathrm{H}), 4.76(\mathrm{~m}, 1 \mathrm{H}), 4.21(\mathrm{~m}, 1.1 \mathrm{H}), 4.10(\mathrm{~m}, 1 \mathrm{H}), 4.00(\mathrm{~m}, 2.9 \mathrm{H}), 3.95$ $(\mathrm{m}, 1 \mathrm{H}), 3.81(\mathrm{t}, 1.6 \mathrm{H}, \mathrm{J}=6.5 \mathrm{~Hz}), 3.68(\mathrm{~m}, 2.4 \mathrm{H}), 3.48(\mathrm{~m}, 4.2 \mathrm{H}), 3.13(\mathrm{bs}, 3.2 \mathrm{H}), 3.04(\mathrm{bs}$, 
3.7H), $2.81(\mathrm{t}, 2.2 \mathrm{H}, \mathrm{J}=6.5 \mathrm{~Hz}), 2.56-2.65(\mathrm{~m}, 10 \mathrm{H}), 2.17(\mathrm{bs}, 4.7 \mathrm{H}), 2.08(\mathrm{~s}, 3 \mathrm{H}), 2.00(\mathrm{~s}, 3 \mathrm{H})$, $1.99(\mathrm{~s}, 1 \mathrm{H}), 1.98(\mathrm{~s}, 3 \mathrm{H}), 1.97(\mathrm{~s}, 3 \mathrm{H}), 1.95(\mathrm{~s}, 2 \mathrm{H}), 1.92(\mathrm{~s}, 2 \mathrm{H}) 1.90(\mathrm{~s}, 3 \mathrm{H}), 1.80(\mathrm{~m}, 4.4 \mathrm{H})$ ppm. MALDI-TOF (pos) m/z 36100 .

4e: ${ }^{1} \mathrm{H}$ NMR (500 MHz, $d_{6}$-DMSO) 7.97 (bs, $1 \mathrm{H}$, amide NH's), 7.90 (bs, 0.3H, amide NH's), 7.83 (bs, $0.3 \mathrm{H}$, amide $\mathrm{NH}$ 's), 7.77 (bs, $1 \mathrm{H}$, amide $\mathrm{NH}$ 's), 7.51 (bs, $1.9 \mathrm{H}, \mathrm{CH}_{2} \mathrm{~N} H \mathrm{C}(\mathrm{S}) \mathrm{NHCH}_{2}$ ), $5.32(\mathrm{~s}, 0.5 \mathrm{H}), 5.25(\mathrm{~m}, 0.6 \mathrm{H}), 5.14(\mathrm{~m}, 1 \mathrm{H}), 5.02(\mathrm{~m}, 1 \mathrm{H}), 4.92(\mathrm{~m}, 1 \mathrm{H}), 4.77(\mathrm{~m}, 0.7 \mathrm{H}), 4.10-$ $4.21(\mathrm{~m}, 1.5 \mathrm{H}), 4.00(\mathrm{~m}, 2.2 \mathrm{H}), 3.81(\mathrm{t}, 1.3 \mathrm{H}, \mathrm{J}=6.5 \mathrm{~Hz}), 3.68(\mathrm{~m}, 1.4 \mathrm{H}), 3.50(\mathrm{~m}, 4.1 \mathrm{H}), 3.13$ (bs, 2.7H), 3.04 (bs, 3.4H), 2.81 (t, 1.3H J =6.5 Hz), 2.56-2.64 (m, 10.5H), 2.37 (bs, 2.5H), 2.16 (bs, 4.8H), $2.07(\mathrm{~s}, 2.7 \mathrm{H}), 2.00(\mathrm{~m}, 9 \mathrm{H}), 1.90(\mathrm{~s}, 2 \mathrm{H}) 1.79(\mathrm{~m}, 3.6 \mathrm{H}) \mathrm{ppm}$. MALDI-TOF (pos) $\mathrm{m} / \mathrm{z} 36300$.

5a: ${ }^{1} \mathrm{H}$ NMR (500 MHz, $d_{6}$-DMSO) 7.97 (bs, $1 \mathrm{H}$, amide NH's), 7.90 (bs, 0.4H, amide NH's), 7.83 (bs, $0.5 \mathrm{H}$, amide NH's), 7.77 (bs, $0.8 \mathrm{H}$, amide NH's), 7.51 (bs, $1.8 \mathrm{H}, \mathrm{CH}_{2} \mathrm{NHC}(\mathrm{S}) \mathrm{NHCH}_{2}$ ) $5.32(\mathrm{~m}, 0.7 \mathrm{H}), 5.17(\mathrm{~m}, 0.8 \mathrm{H}), 5.07(\mathrm{~m}, 1.6 \mathrm{H}), 5.02(\mathrm{~m}, 0.8 \mathrm{H}), 4.92(\mathrm{~m}, 1 \mathrm{H}), 4.84(\mathrm{~m}, 0.5 \mathrm{H})$, $4.21(\mathrm{~m}, 0.7 \mathrm{H}), 4.10(\mathrm{~m}, 0.9 \mathrm{H}), 4.00(\mathrm{~m}, 2.3 \mathrm{H}), 3.90(\mathrm{~m}, 0.7), 3.80(\mathrm{t}, 0.8 \mathrm{H}, \mathrm{J}=6.5 \mathrm{~Hz}), 3.68(\mathrm{~m}$, $1.8 \mathrm{H}), 3.50(\mathrm{~m}, 3.2 \mathrm{H}), 3.14(\mathrm{bs}, 2.5 \mathrm{H}), 3.04(\mathrm{bs}, 3.9 \mathrm{H}), 2.81(\mathrm{t}, 0.5 \mathrm{H} \mathrm{J}=6.5 \mathrm{~Hz}), 2.56-2.64(\mathrm{~m}$, $11.4 \mathrm{H}), 2.17(\mathrm{bs}, 4.8 \mathrm{H}), 2.08(\mathrm{~s}, 3.2 \mathrm{H}), 2.07(\mathrm{~s}, 3 \mathrm{H}), 2.00(\mathrm{~m}, 9 \mathrm{H}), 1.90(\mathrm{~s}, 3.5 \mathrm{H}) 1.79(\mathrm{~m}, 3.5 \mathrm{H})$ ppm. MALDI-TOF (pos) $\mathrm{m} / \mathrm{z} 63500$.

5b: ${ }^{1} \mathrm{H}$ NMR (500 MHz, $d_{6}$-DMSO) 7.97 (bs, $1 \mathrm{H}$, amide NH's), 7.90 (bs, 0.5H, amide NH's), 7.83 (bs, $0.5 \mathrm{H}$, amide NH's), 7.77 (bs, $0.8 \mathrm{H}$, amide $\mathrm{NH}$ 's), 7.51 (bs, $1.8 \mathrm{H}, \mathrm{CH}_{2} \mathrm{NHC}(\mathrm{S}) \mathrm{NHCH}_{2}$ ) 5.32(m, 0.8H), $5.17(\mathrm{~m}, 0.8 \mathrm{H}), 5.07(\mathrm{~m}, 1.1 \mathrm{H}), 5.02(\mathrm{~m}, 0.8 \mathrm{H}), 4.99(\mathrm{~m}, 0.17 \mathrm{H}), 4.93(\mathrm{~m}, 0.9 \mathrm{H})$, $4.84(\mathrm{~m}, 0.5 \mathrm{H}), 4.21(\mathrm{~m}, 0.8 \mathrm{H}), 4.10(\mathrm{~m}, 0.8 \mathrm{H}), 4.00(\mathrm{~m}, 2.4 \mathrm{H}), 3.80(\mathrm{t}, 1.1 \mathrm{H}, \mathrm{J}=6.5 \mathrm{~Hz}), 3.68$ $(\mathrm{m}, 1.6 \mathrm{H}), 3.50(\mathrm{~m}, 3.8 \mathrm{H}), 3.14(\mathrm{bs}, 2.5 \mathrm{H}), 3.04(\mathrm{bs}, 3.9 \mathrm{H}), 2.81(\mathrm{t}, 1 \mathrm{H} \mathrm{J}=6.5 \mathrm{~Hz}), 2.56-2.64(\mathrm{~m}$, 13H), 2.17 (bs, 5H), $2.08(\mathrm{~s}, 4 \mathrm{H}), 2.07(\mathrm{~s}, 2 \mathrm{H}), 2.00(\mathrm{~s}, 3.5 \mathrm{H}), 1.99(\mathrm{~s}, 3 \mathrm{H}) 1.98(\mathrm{~s}, 3 \mathrm{H}), 1.97(\mathrm{~s}$, 3H), 1.90 (s, 3.5H) 1.79 (m, 4H) ppm. MALDI-TOF (pos) m/z 65500.

5c: ${ }^{1} \mathrm{H}$ NMR (500 MHz, $d_{6}$-DMSO) 7.97 (bs, $1 \mathrm{H}$, amide NH's), 7.78 (bs, $0.8 \mathrm{H}$, amide NH's), $7.51\left(\mathrm{bs}, 2 \mathrm{H}, \mathrm{CH}_{2} \mathrm{NHC}(\mathrm{S}) \mathrm{NHCH}_{2}\right) 5.32(\mathrm{~m}, 0.9 \mathrm{H}), 5.26(\mathrm{~m}, 1 \mathrm{H}), 5.17(\mathrm{~m}, 1 \mathrm{H}), 5.02(\mathrm{~m}, 0.8 \mathrm{H})$, $4.99(\mathrm{~m}, 0.8 \mathrm{H}) 4.92(\mathrm{~m}, 1.6 \mathrm{H}), 4.76(\mathrm{~m}, 1 \mathrm{H}), 4.21(\mathrm{~m}, 1 \mathrm{H}), 4.10(\mathrm{~m}, 1 \mathrm{H}), 4.00(\mathrm{~m}, 2.7 \mathrm{H}), 3.95$ (m, 1H), $3.81(\mathrm{t}, 1.6 \mathrm{H}, \mathrm{J}=6.5 \mathrm{~Hz}), 3.68(\mathrm{~m}, 2.4 \mathrm{H}), 3.48(\mathrm{~m}, 4.2 \mathrm{H}), 3.13(\mathrm{bs}, 3.2 \mathrm{H}), 3.04$ (bs, 3.7H), $2.81(\mathrm{t}, 2.2 \mathrm{H}, \mathrm{J}=6.5 \mathrm{~Hz}), 2.56-2.65(\mathrm{~m}, 10 \mathrm{H}), 2.17(\mathrm{bs}, 4.7 \mathrm{H}), 2.08(\mathrm{~s}, 3 \mathrm{H}), 2.00(\mathrm{~s}, 3 \mathrm{H})$, $1.99(\mathrm{~s}, 1 \mathrm{H}), 1.98(\mathrm{~s}, 3 \mathrm{H}), 1.97(\mathrm{~s}, 3 \mathrm{H}), 1.95(\mathrm{~s}, 2 \mathrm{H}), 1.92(\mathrm{~s}, 2 \mathrm{H}) 1.90(\mathrm{~s}, 3 \mathrm{H}), 1.80(\mathrm{~m}, 4.4 \mathrm{H})$ ppm. MALDI-TOF (pos) m/z 67000 .

5d: ${ }^{1} \mathrm{H}$ NMR (500 MHz, $d_{6}$-DMSO) 7.97 (bs, $1 \mathrm{H}$, amide NH's), 7.90 (bs, 0.3H, amide NH's), 7.83 (bs, $0.4 \mathrm{H}$, amide $\mathrm{NH}$ 's), 7.77 (bs, $1 \mathrm{H}$, amide $\mathrm{NH}$ 's), 7.51 (bs, $1.8 \mathrm{H}, \mathrm{CH}_{2} \mathrm{~N} H \mathrm{C}(\mathrm{S}) \mathrm{NHCH}_{2}$ ), $5.31(\mathrm{~s}, 0.4 \mathrm{H}), 5.25(\mathrm{~m}, 0.4 \mathrm{H}), 5.16(\mathrm{~m}, 1 \mathrm{H}), 5.02(\mathrm{~m}, 1 \mathrm{H}), 4.92(\mathrm{~m}, 1.1 \mathrm{H}), 4.77(\mathrm{~m}, 0.6 \mathrm{H}), 4.10-$ $4.21(\mathrm{~m}, 0.9 \mathrm{H}), 4.00(\mathrm{~m}, 1.7 \mathrm{H}), 3.80(\mathrm{t}, 0.5 \mathrm{H}, \mathrm{J}=6.5 \mathrm{~Hz}), 3.68(\mathrm{~m}, 1.2 \mathrm{H}), 3.50(\mathrm{~m}, 3.5 \mathrm{H}), 3.13$ (bs, 2.6H), 3.04 (bs, 3.2H), 2.81 (t, 0.5H J = 6.5 Hz), 2.56-2.64 (m, 9.2H), 2.37 (bs, 2.4H), 2.16 (bs, 4.4H), $2.07(\mathrm{~s}, 2.1 \mathrm{H}), 2.00(\mathrm{~m}, 11 \mathrm{H}), 1.90(\mathrm{~s}, 2 \mathrm{H}) 1.79(\mathrm{~m}, 2.8 \mathrm{H}) \mathrm{ppm}$. MALDI-TOF (pos) $\mathrm{m} / \mathrm{z} 66000$.

6a: ${ }^{1} \mathrm{H}$ NMR (500 MHz, $d_{6}$-DMSO) 7.97 (bs, $1 \mathrm{H}$, amide NH's), 7.90 (bs, 0.4H, amide NH's), 7.83 (bs, $0.5 \mathrm{H}$, amide NH's), 7.77 (bs, $0.8 \mathrm{H}$, amide NH's), 7.51 (bs, $1.8 \mathrm{H}, \mathrm{CH}_{2} \mathrm{NHC}(\mathrm{S}) \mathrm{NHCH}_{2}$ ) 
5.32(m, 0.7H), $5.17(\mathrm{~m}, 0.8 \mathrm{H}), 5.07(\mathrm{~m}, 1.6 \mathrm{H}), 5.02(\mathrm{~m}, 0.8 \mathrm{H}), 4.92(\mathrm{~m}, 1 \mathrm{H}), 4.84(\mathrm{~m}, 0.5 \mathrm{H})$, $4.21(\mathrm{~m}, 0.7 \mathrm{H}), 4.10(\mathrm{~m}, 0.9 \mathrm{H}), 4.00(\mathrm{~m}, 2.3 \mathrm{H}), 3.90(\mathrm{~m}, 0.7), 3.80(\mathrm{t}, 0.8 \mathrm{H}, \mathrm{J}=6.5 \mathrm{~Hz}), 3.68(\mathrm{~m}$, $1.8 \mathrm{H}), 3.50(\mathrm{~m}, 3.2 \mathrm{H}), 3.14(\mathrm{bs}, 2.5 \mathrm{H}), 3.04(\mathrm{bs}, 3.9 \mathrm{H}), 2.81(\mathrm{t}, 0.5 \mathrm{H} \mathrm{J}=6.5 \mathrm{~Hz}), 2.56-2.64(\mathrm{~m}$, 11.4H), $2.17(\mathrm{bs}, 4.8 \mathrm{H}), 2.08(\mathrm{~s}, 3.2 \mathrm{H}), 2.07(\mathrm{~s}, 3 \mathrm{H}), 2.00(\mathrm{~m}, 9 \mathrm{H}), 1.90(\mathrm{~s}, 3.5 \mathrm{H}) 1.79(\mathrm{~m}, 3.5 \mathrm{H})$ ppm. MALDI-TOF (pos) m/z 113500.

6b: ${ }^{1} \mathrm{H}$ NMR (500 MHz, $d_{6}$-DMSO) $\square 7.97$ (bs, 1H, amide NH's), 7.83 (bs, 1H, amide NH's), 7.77 (bs, $1 \mathrm{H}$, amide NH's), 7.51 (bs, $\left.1.8 \mathrm{H}, \mathrm{CH}_{2} \mathrm{NHC}(\mathrm{S}) \mathrm{NHCH}_{2}\right) 5.32(\mathrm{~m}, 0.8 \mathrm{H}), 5.25$ (m, 0.5H), $5.17(\mathrm{~m}, 0.8 \mathrm{H}), 5.07(\mathrm{~m}, 0.5 \mathrm{H}), 5.02(\mathrm{~m}, 0.8 \mathrm{H}), 4.99(\mathrm{~m}, 0.5 \mathrm{H}), 4.92(\mathrm{~m}, 1.3 \mathrm{H}), 4.84(\mathrm{~m}, 0.3 \mathrm{H})$, $4.75(\mathrm{~m}, 0.7 \mathrm{H}), 4.21(\mathrm{~m}, 0.8 \mathrm{H}), 4.09(\mathrm{~m}, 0.8 \mathrm{H}), 4.00(\mathrm{~m}, 2.6 \mathrm{H}), 3.80(\mathrm{t}, 1.1 \mathrm{H}, \mathrm{J}=6.5 \mathrm{~Hz}), 3.68$ $(\mathrm{m}, 2 \mathrm{H}), 3.50(\mathrm{~m}, 4 \mathrm{H}), 3.13(\mathrm{bs}, 2.5 \mathrm{H}), 3.04(\mathrm{bs}, 4.7 \mathrm{H}), 2.81(\mathrm{t}, 1 \mathrm{H}, \mathrm{J}=6.5 \mathrm{~Hz}), 2.56-2.64(\mathrm{~m}$, 17H), 2.17 (bs, 6.5H), $2.08(\mathrm{~s}, 3.7 \mathrm{H}), 2.00(\mathrm{~s}, 3 \mathrm{H}), 1.99(\mathrm{~s}, 2 \mathrm{H}), 1.98(\mathrm{~s}, 3 \mathrm{H}), 1.97(\mathrm{~s}, 3 \mathrm{H}) 1.96(\mathrm{~s}$, 2H), 1.90 (s, 3H) 1.79 (m, 4.7H) ppm. MALDI-TOF (pos) m/z 115500.

6c: ${ }^{1} \mathrm{H}$ NMR (500 MHz, $d_{6}$-DMSO) 77.97 (bs, 1H, amide NH's), 7.78 (bs, 0.8H, amide NH's), 7.51 (bs, 2H, $\left.\mathrm{CH}_{2} \mathrm{NHC}(\mathrm{S}) \mathrm{NHCH}_{2}\right) 5.32(\mathrm{~m}, 0.9 \mathrm{H}), 5.26(\mathrm{~m}, 1 \mathrm{H}), 5.17(\mathrm{~m}, 1 \mathrm{H}), 5.02(\mathrm{~m}, 0.8 \mathrm{H})$, $4.99(\mathrm{~m}, 0.9 \mathrm{H}) 4.92(\mathrm{~m}, 1.6 \mathrm{H}), 4.76(\mathrm{~m}, 1 \mathrm{H}), 4.21(\mathrm{~m}, 1 \mathrm{H}), 4.10(\mathrm{~m}, 1 \mathrm{H}), 4.00(\mathrm{~m}, 2.6 \mathrm{H}), 3.95$ $(\mathrm{m}, 1 \mathrm{H}), 3.81(\mathrm{t}, 1.6 \mathrm{H}, \mathrm{J}=6.5 \mathrm{~Hz}), 3.68(\mathrm{~m}, 2.4 \mathrm{H}), 3.48(\mathrm{~m}, 4.2 \mathrm{H}), 3.13(\mathrm{bs}, 3.2 \mathrm{H}), 3.04(\mathrm{bs}$, 3.7H), $2.81(\mathrm{t}, 2.2 \mathrm{H}, \mathrm{J}=6.5 \mathrm{~Hz}), 2.56-2.65(\mathrm{~m}, 10 \mathrm{H}), 2.17(\mathrm{bs}, 4.7 \mathrm{H}), 2.08(\mathrm{~s}, 3 \mathrm{H}), 2.00(\mathrm{~s}, 3 \mathrm{H})$, $1.99(\mathrm{~s}, 1 \mathrm{H}), 1.98(\mathrm{~s}, 3 \mathrm{H}), 1.97(\mathrm{~s}, 3 \mathrm{H}), 1.95(\mathrm{~s}, 2 \mathrm{H}), 1.92(\mathrm{~s}, 2 \mathrm{H}) 1.90(\mathrm{~s}, 3 \mathrm{H}), 1.80(\mathrm{~m}, 4.4 \mathrm{H})$ ppm. MALDI-TOF (pos) m/z 115000.

6d: ${ }^{1} \mathrm{H}$ NMR (500 MHz, $d_{6}$-DMSO) $\square 7.97$ (bs, 1H, amide NH's), 7.90 (bs, 0.4H, amide NH's), 7.83 (bs, 0.5H, amide NH's), 7.77 (bs, $1 \mathrm{H}$, amide $\mathrm{NH}$ 's), 7.51 (bs, 1.8H, $\mathrm{CH}_{2} \mathrm{NHC}(\mathrm{S}) \mathrm{NHCH}_{2}$ ), $5.32(\mathrm{~s}, 1 \mathrm{H}), 5.25(\mathrm{~m}, 1.1 \mathrm{H}), 5.14(\mathrm{~m}, 0.5 \mathrm{H}), 5.02(\mathrm{~m}, 1.1 \mathrm{H}), 4.92(\mathrm{~m}, 1.4 \mathrm{H}), 4.77(\mathrm{~m}, 0.8 \mathrm{H})$, $4.10-4.21(\mathrm{~m}, 2.4 \mathrm{H}), 4.00(\mathrm{~m}, 3.3 \mathrm{H}), 3.81(\mathrm{t}, 2.5 \mathrm{H}, \mathrm{J}=6.5 \mathrm{~Hz}), 3.68(\mathrm{~m}, 2.1 \mathrm{H}), 3.50(\mathrm{~m}, 4.6 \mathrm{H})$, $3.13(\mathrm{bs}, 3.1 \mathrm{H}), 3.04(\mathrm{bs}, 3.8 \mathrm{H}), 2.81(\mathrm{t}, 2.5 \mathrm{H} \mathrm{J}=6.4 \mathrm{~Hz}), 2.56-2.64(\mathrm{~m}, 10.5 \mathrm{H}), 2.37(\mathrm{bs}, 2.5 \mathrm{H})$, $2.16(\mathrm{bs}, 4.7 \mathrm{H}), 2.07(\mathrm{~s}, 2.7 \mathrm{H}), 2.00(\mathrm{~m}, 17 \mathrm{H}), 1.90(\mathrm{~s}, 2 \mathrm{H}) 1.79(\mathrm{~m}, 5.9 \mathrm{H}) \mathrm{ppm}$. MALDI-TOF (pos) $\mathrm{m} / \mathrm{z} 116000$.

General procedure for deacylation of dendrimers 4-6. To the lyophilized solid product of compounds 4-6 $1 \mathrm{~mL}$ of 1:1 water:methanol was added, at which point the dendrimer would become a white precipitate solid. To this mixture was added 0.2 equivalents of $\mathrm{NaOMe}(0.8 \mathrm{M}$ in $\mathrm{MeOH}$ ) for each peripheral carbohydrate, and let stir for $3 \mathrm{hrs}$. If, at this time, the mixture had not become a clear solution a further 0.2 equivalents of $\mathrm{NaOMe}(0.8 \mathrm{M}$ in $\mathrm{MeOH})$ was added and this step was repeated until the mixture became a clear and colorless solution. $\mathrm{HCl}_{(\mathrm{aq})}(0.1 \mathrm{M})$ was then added slowly until the $\mathrm{pH}$ was $\sim 7$. This neutralized solution was placed in a centrifugal

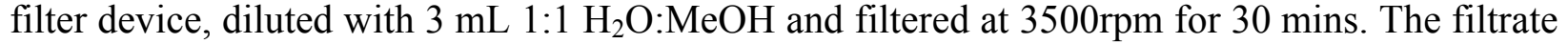
was then removed and $3 \mathrm{~mL} \mathrm{H}_{2} \mathrm{O}$ was added and filtered for 30 mins at 3500rpm. This procedure was repeated 2 more times. At which point the remaining residue was taken up in Millipore water and lyophilized to give a white fluffy solid.

4a: ${ }^{1} \mathrm{H}$ NMR (500 MHz, $d_{6}$-DMSO) 7.96 (bs, 1H, amide NH's), 7.89 (bs, 0.4H, amide NH's), 7.83 (bs, $0.4 \mathrm{H}$, amide NH's), 7.76 (bs, $1.1 \mathrm{H}$, amide $\mathrm{NH}$ 's), 7.52 (bs, $\left.1.9 \mathrm{H} \mathrm{CH}_{2} \mathrm{NHC}(\mathrm{S}) \mathrm{NHCH}_{2}\right)$, 4.67 (bs, 1.4H), $4.58(\mathrm{~s}, 0.5 \mathrm{H}), 4.54(\mathrm{~m}, 1.9 \mathrm{H}), 4.41$ (bs, 0.9H), 4.33 (bs, 0.3H), 3.65 (bs, 0.4), 
$3.59(\mathrm{~m}, 2.2 \mathrm{H}), 3.54(\mathrm{~s}, 1.6 \mathrm{H}), 3.39-3.51(\mathrm{~m}, 5.7 \mathrm{H}), 3.12$ (bs, 2.7H), 3.02 (bs, 4.0H), 2.48-2.63 (m, 10.1H), 2.38 (bs, 2.2H), 2.15 (bs, 5.1H), 1.73 (m, 2.9H) ppm; MALDI-TOF (pos) m/z 28000.

4b: ${ }^{1} \mathrm{H}$ NMR (500 MHz, $d_{6}$-DMSO) 77.99 (bs, $1 \mathrm{H}$, amide NH's), 7.92 (bs, 0.5H, amide NH's), 7.85 (bs, $0.6 \mathrm{H}$, amide $\mathrm{NH}$ 's), 7.79 (bs, $1.2 \mathrm{H}$, amide $\mathrm{NH}$ 's), 7.54 (bs, $1.9 \mathrm{H} \mathrm{CH}_{2} \mathrm{NHC}(\mathrm{S}) \mathrm{N} H C H_{2}$ ), $4.83(\mathrm{~s}, 0.15 \mathrm{H}), 4.67(\mathrm{~s}, 0.5 \mathrm{H}), 4.60(\mathrm{~s}, 0.5 \mathrm{H}), 4.56(\mathrm{~m}, 1.5 \mathrm{H}), 4.43(\mathrm{bs}, 0.9 \mathrm{H}), 4.35$ (bs, 0.3), 3.60-3.67 (m, 2.5H), $3.56(\mathrm{~s}, 1.4 \mathrm{H}), 3.48(\mathrm{~m}, 2.7 \mathrm{H}), 3.34-3.44(\mathrm{~m}, 6 \mathrm{H}), 3.13(\mathrm{bs}, 2.8 \mathrm{H}), 3.05$ (bs, $5.1 \mathrm{H}), 2.60(\mathrm{~m}, 10.9 \mathrm{H}), 2.40(\mathrm{bs}, 2.5 \mathrm{H}), 2.17(\mathrm{bs}, 6 \mathrm{H}), 1.77(\mathrm{~m}, 3.5 \mathrm{H}) \mathrm{ppm}$. MALDI-TOF (pos) $\mathrm{m} / \mathrm{z} 27600$.

4c: ${ }^{1} \mathrm{H}$ NMR (500 MHz, $d_{6}$-DMSO) 77.97 (bs, $1 \mathrm{H}$, amide NH's), 7.90 (bs, 0.5H, amide NH's), 7.83 (bs, $0.5 \mathrm{H}$, amide $\mathrm{NH}$ 's), 7.77 (bs, $1.2 \mathrm{H}$, amide $\mathrm{NH}$ 's), 7.52 (bs, $2 \mathrm{H} \mathrm{CH}_{2} \mathrm{~N} H \mathrm{C}(\mathrm{S}) \mathrm{NHCH}_{2}$ ), $4.83(\mathrm{~s}, 0.4 \mathrm{H}), 4.68(\mathrm{~m}, 1.6 \mathrm{H}), 4.58(\mathrm{~m}, 0.7), 4.55(\mathrm{~m}, 1.2 \mathrm{H}), 4.41$ (bs, $0.9 \mathrm{H}), 4.33$ (bs, 0.2), 3.60 $(\mathrm{m}, 2.4 \mathrm{H}), 3.46-3.55(\mathrm{~m}, 3.8 \mathrm{H}), 3.40(\mathrm{~m}, 3.1 \mathrm{H}), 3.12(\mathrm{bs}, 3.2 \mathrm{H}), 3.03(\mathrm{bs}, 5.7 \mathrm{H}), 2.60(\mathrm{~m}$, $11.1 \mathrm{H}), 2.39$ (bs, 2.8H), 2.16 (bs, 6.1H), 1.74 (m, 3.5H) ppm. MALDI-TOF (pos) m/z 27700.

4d: ${ }^{1} \mathrm{H}$ NMR (500 MHz, $d_{6}$-DMSO) 77.98 (bs, $1 \mathrm{H}$, amide NH's), 7.91 (bs, 0.3H, amide NH's), 7.85 (bs, 0.3H, amide NH's), 7.78 (bs, $1 \mathrm{H}$, amide $\mathrm{NH}^{\prime}$ ), 7.54 (bs, $1.9 \mathrm{H} \mathrm{CH}_{2} \mathrm{NHC}(\mathrm{S}) \mathrm{NHCH}_{2}$ ), $4.98(\mathrm{~s}, 0.14 \mathrm{H}), 4.92(\mathrm{~s}, 0.14 \mathrm{H}), 4.84(\mathrm{~s}, 0.8 \mathrm{H}), 4.57-4.75(\mathrm{~m}, 2.8 \mathrm{H}), 4.43(\mathrm{~m}, 1 \mathrm{H}), 4.43(\mathrm{bs}$, 0.14), 3.48-3.77 (m, 5.2H), 3.36-3.48 (m, 5H), 3.14 (bs, 3.4H), 3.05 (bs, 4.6H), 2.60 (bs, 9.7H), 2.40 (bs, 2.3H), 2.17 (bs, 5.1H), 1.77 (m, 2.8H) ppm. MALDI-TOF (pos) m/z 30200 .

4e: ${ }^{1} \mathrm{H}$ NMR (500 MHz, $d_{6}$-DMSO) $\square 8.09$ (bs, $0.8 \mathrm{H}$, amide NH's), 7.92 (bs, 0.1H, amide NH's), 7.62 (bs, $\left.0.8 \mathrm{H} \mathrm{CH}_{2} \mathrm{NHC}(\mathrm{S}) \mathrm{N} H \mathrm{CH}_{2}\right), 4.87(\mathrm{~s}, 0.14 \mathrm{H}), 4.76(\mathrm{~s}, 0.14 \mathrm{H}), 4.66(\mathrm{~s}, 0.8 \mathrm{H}), 4.57(\mathrm{~m}$, 2.8H), $4.45(\mathrm{~m}, 1 \mathrm{H}), 3.36-3.77(\mathrm{~m}, 12.6 \mathrm{H}), 3.14(\mathrm{bs}, 1.2 \mathrm{H}), 3.05(\mathrm{bs}, 0.9 \mathrm{H}), 2.90(\mathrm{bs}, 1.7 \mathrm{H}), 2.57$ (m, 2.1H), $2.46(\mathrm{~s}, 1 \mathrm{H}), 2.30$ (bs, 1.6H), $1.77(\mathrm{~m}, 1 \mathrm{H}) \mathrm{ppm}$. MALDI-TOF (pos) m/z 28900.

5a: ${ }^{1} \mathrm{H}$ NMR (500 MHz, $d_{6}$-DMSO) 7.98 (bs, $1 \mathrm{H}$, amide NH's), 7.91 (bs, 0.6H, amide NH's), 7.85 (bs, $0.7 \mathrm{H}$, amide $\mathrm{NH}$ 's), 7.77 (bs, $1.2 \mathrm{H}$, amide $\mathrm{NH}$ 's), 7.52 (bs, $1.9 \mathrm{H} \mathrm{CH}_{2} \mathrm{~N} H \mathrm{C}(\mathrm{S}) \mathrm{NHCH}_{2}$ ), $4.70(\mathrm{bs}, 1.4 \mathrm{H}), 4.60(\mathrm{~s}, 0.6 \mathrm{H}), 4.56(\mathrm{~m}, 1.9 \mathrm{H}), 4.41(\mathrm{bs}, 1 \mathrm{H}), 4.33(\mathrm{bs}, 0.4 \mathrm{H}), 3.65$ (bs, 0.6), 3.59 $(\mathrm{m}, 2.2 \mathrm{H}), 3.35-3.55(\mathrm{~m}, 10.6 \mathrm{H}), 3.12(\mathrm{bs}, 2.9 \mathrm{H}), 3.04(\mathrm{bs}, 5.1 \mathrm{H}), 2.48-2.63(\mathrm{~m}, 11.1 \mathrm{H}), 2.38$ (bs, 2.5H), 2.17 (bs, 6.2H), $1.73(\mathrm{~m}, 3.6 \mathrm{H}) \mathrm{ppm}$; MALDI-TOF (pos) m/z 51500 .

5b: ${ }^{1} \mathrm{H}$ NMR (500 MHz, $d_{6}$-DMSO) 7.99 (bs, $1 \mathrm{H}$, amide NH's), 7.92 (bs, 0.5H, amide NH's), 7.85 (bs, $0.6 \mathrm{H}$, amide $\mathrm{NH}$ 's), 7.79 (bs, 1.2H, amide NH's), 7.54 (bs, $1.9 \mathrm{H} \mathrm{CH}_{2} \mathrm{~N} H \mathrm{C}(\mathrm{S}) \mathrm{NHCH}_{2}$ ), $4.83(\mathrm{~s}, 0.15 \mathrm{H}), 4.67(\mathrm{~s}, 0.5 \mathrm{H}), 4.60(\mathrm{~s}, 0.5 \mathrm{H}), 4.56(\mathrm{~m}, 1.5 \mathrm{H}), 4.43(\mathrm{bs}, 0.9 \mathrm{H}), 4.35$ (bs, 0.3), 3.60-3.67 (m, 2.5H), $3.56(\mathrm{~s}, 1.4 \mathrm{H}), 3.48(\mathrm{~m}, 2.7 \mathrm{H}), 3.34-3.44(\mathrm{~m}, 6 \mathrm{H}), 3.13(\mathrm{bs}, 2.8 \mathrm{H}), 3.05(\mathrm{bs}$, $5.1 \mathrm{H}), 2.60(\mathrm{~m}, 10.9 \mathrm{H}), 2.40(\mathrm{bs}, 2.5 \mathrm{H}), 2.17$ (bs, 6H), 1.77 (m, 3.5H) ppm. MALDI-TOF (pos) $\mathrm{m} / \mathrm{z} 51500$.

5c: ${ }^{1} \mathrm{H}$ NMR (500 MHz, $d_{6}$-DMSO) 77.98 (bs, $1 \mathrm{H}$, amide NH's), 7.91 (bs, $0.3 \mathrm{H}$, amide NH's), 7.85 (bs, $0.3 \mathrm{H}$, amide $\mathrm{NH}$ 's), 7.78 (bs, $1 \mathrm{H}$, amide NH's), 7.54 (bs, $1.9 \mathrm{H} \mathrm{CH}_{2} \mathrm{NHC}(\mathrm{S}) \mathrm{NHCH}_{2}$ ), $4.98(\mathrm{~s}, 0.15 \mathrm{H}), 4.92(\mathrm{~s}, 0.15 \mathrm{H}), 4.84(\mathrm{~s}, 0.9 \mathrm{H}), 4.57-4.75(\mathrm{~m}, 2.8 \mathrm{H}), 4.43(\mathrm{~m}, 1 \mathrm{H}), 4.43(\mathrm{bs}$, 0.15H), 3.48-3.77 (m, 5.5H), 3.36-3.48 (m, 5H), 3.14 (bs, 3.7H), 3.05 (bs, 4.9H), 2.60 (bs, 10H), 2.40 (bs, 2.5H), 2.17 (bs, 5H), 1.77 (m, 2.8H) ppm. MALDI-TOF (pos) m/z 56000. 
5d: ${ }^{1} \mathrm{H}$ NMR (500 MHz, $d_{6}$-DMSO) $\square 7.98$ (bs, 1H, amide NH's), 7.91 (bs, 0.3H, amide NH's), 7.85 (bs, 0.3H, amide NH's), 7.78 (bs, 1H, amide NH's), 7.54 (bs, $1.9 \mathrm{H} \mathrm{CH}_{2} \mathrm{NHC}(\mathrm{S}) \mathrm{NHCH}_{2}$ ), $4.86(\mathrm{~s}, 0.7 \mathrm{H}), 4.76(\mathrm{~s}, 0.6 \mathrm{H}), 4.66(\mathrm{~s}, 0.5 \mathrm{H}), 4.60(\mathrm{~s}, 0.9 \mathrm{H}), 4.55(\mathrm{~m}, 0.9 \mathrm{H}), 4.44(\mathrm{~m}, 0.8 \mathrm{H}), 4.37$ (bs, 0.5H), 3.35-3.77 (m, 10.8H), $3.14(\mathrm{bs}, 3.4 \mathrm{H}), 3.05(\mathrm{bs}, 4.2 \mathrm{H}), 2.60(\mathrm{bs}, 9.7 \mathrm{H}), 2.40$ (bs, 2.1H), 2.17 (bs, 5.1H), $1.77(\mathrm{~m}, 3.0 \mathrm{H}) \mathrm{ppm}$. MALDI-TOF (pos) m/z 54000.

6a: ${ }^{1} \mathrm{H}$ NMR (500 MHz, $d_{6}$-DMSO) $\square 7.96$ (bs, 1H, amide NH's), 7.89 (bs, 0.4H, amide NH's), 7.83 (bs, $0.4 \mathrm{H}$, amide NH's), 7.76 (bs, $1.1 \mathrm{H}$, amide $\mathrm{NH}$ 's), 7.52 (bs, $\left.1.9 \mathrm{H} \mathrm{CH}_{2} \mathrm{NHC}(\mathrm{S}) \mathrm{NHCH}_{2}\right)$, 4.67 (bs, 1.4H), 4.58 (s, 0.5H), $4.54(\mathrm{~m}, 1.9 \mathrm{H}), 4.41$ (bs, 0.9H), 4.33 (bs, 0.3H), 3.65 (bs, 0.4), $3.59(\mathrm{~m}, 2.2 \mathrm{H}), 3.54(\mathrm{~s}, 1.6 \mathrm{H}), 3.39-3.51(\mathrm{~m}, 5.7 \mathrm{H}), 3.12(\mathrm{bs}, 2.7 \mathrm{H}), 3.02(\mathrm{bs}, 4.0 \mathrm{H}), 2.48-2.63$ (m, 10.1H), 2.38 (bs, 2.2H), 2.15 (bs, 5.1H), 1.73 (m, 2.9H) ppm; MALDI-TOF (pos) m/z 93000.

6b: ${ }^{1} \mathrm{H}$ NMR (500 MHz, $d_{6}$-DMSO) $\square 7.97$ (bs, 1H, amide NH's), 7.90 (bs, 0.5H, amide NH's), 7.83 (bs, 0.5H, amide NH's), 7.77 (bs, 1.2H, amide NH's), 7.52 (bs, 2H CH $\mathrm{CH}_{2} \mathrm{NHC}(\mathrm{S}) \mathrm{NHCH}_{2}$ ), $4.83(\mathrm{~s}, 0.4 \mathrm{H}), 4.68(\mathrm{~m}, 1.6 \mathrm{H}), 4.58(\mathrm{~m}, 0.7), 4.55(\mathrm{~m}, 1.2 \mathrm{H}), 4.41$ (bs, 0.9H), 4.33 (bs, 0.2), 3.60 $(\mathrm{m}, 2.4 \mathrm{H}), 3.46-3.55(\mathrm{~m}, 3.8 \mathrm{H}), 3.40(\mathrm{~m}, 3.1 \mathrm{H}), 3.12(\mathrm{bs}, 3.2 \mathrm{H}), 3.03(\mathrm{bs}, 5.7 \mathrm{H}), 2.60(\mathrm{~m}$, 11.1H), 2.39 (bs, 2.8H), 2.16 (bs, 6.1H), 1.74 (m, 3.5H) ppm. MALDI-TOF (pos) m/z 95500.

6c: ${ }^{1} \mathrm{H}$ NMR (500 MHz, $d_{6}$-DMSO) 77.98 (bs, 1H, amide NH's), 7.91 (bs, 0.3H, amide NH's), 7.85 (bs, $0.3 \mathrm{H}$, amide NH's), 7.78 (bs, $1 \mathrm{H}$, amide NH's), 7.54 (bs, $1.9 \mathrm{H} \mathrm{CH}_{2} \mathrm{NHC}(\mathrm{S}) \mathrm{NHCH}_{2}$ ), $4.98(\mathrm{~s}, 0.14 \mathrm{H}), 4.92(\mathrm{~s}, 0.14 \mathrm{H}), 4.84(\mathrm{~s}, 0.8 \mathrm{H}), 4.57-4.75(\mathrm{~m}, 2.8 \mathrm{H}), 4.43(\mathrm{~m}, 1 \mathrm{H}), 4.43(\mathrm{bs}$, 0.14), 3.48-3.77 (m, 5.2H), 3.36-3.48 (m, 5H), 3.14 (bs, 3.4H), 3.05 (bs, 4.6H), 2.60 (bs, 9.7H), $2.40(\mathrm{bs}, 2.3 \mathrm{H}), 2.17$ (bs, 5.1H), 1.77 (m, 2.8H) ppm. MALDI-TOF (pos) m/z 95500.

6d: ${ }^{1} \mathrm{H}$ NMR (500 MHz, $d_{6}$-DMSO) $\square 8.16$ (bs, 1H, amide NH's), 7.96 (bs, 0.2H, amide NH's), 7.65 (bs, 0.8H CH $\left.\mathrm{CH}_{2} \mathrm{NHC}(\mathrm{S}) \mathrm{NHCH}_{2}\right), 4.90(\mathrm{~s}, 0.4 \mathrm{H}), 4.80(\mathrm{~s}, 0.3 \mathrm{H}), 4.69(\mathrm{~s}, 0.4 \mathrm{H}), 4.60(\mathrm{~m}$, $0.9 \mathrm{H}), 4.48(\mathrm{bs}, 0.6 \mathrm{H}), 3.36-3.77(\mathrm{~m}, 7 \mathrm{H}), 3.16(\mathrm{bs}, 2.4 \mathrm{H}), 3.05(\mathrm{bs}, 2.1 \mathrm{H}), 2.90(\mathrm{bs}, 1.7 \mathrm{H}), 2.57$ $(\mathrm{m}, 2.9 \mathrm{H}), 2.30(\mathrm{bs}, 1.5 \mathrm{H}), 1.76(\mathrm{~m}, 1.5 \mathrm{H}) \mathrm{ppm} .$. MALDI-TOF (pos) $\mathrm{m} / \mathrm{z} 94500$.

Table S2. Hemagglutination assay and $\mathrm{M}_{\mathrm{W}}$ results (from MALDI-TOF MS) for 4-6.

\begin{tabular}{|c|c|c|c|c|c|c|c|}
\hline Cmpd & $\begin{array}{l}\text { Mw After } \\
\text { Mannose } \\
\text { Addition }\end{array}$ & $\begin{array}{l}\# \text { mannose } \\
\text { residues }^{a}\end{array}$ & $\begin{array}{l}\text { Mw After } \\
\text { Glucose } \\
\text { Addition }\end{array}$ & $\begin{array}{l}\# \text { glucose } \\
\text { residues }^{a}\end{array}$ & $\begin{array}{l}\mathrm{M}_{\mathrm{w}} \text { after } \\
\text { Galactose } \\
\text { addition }\end{array}$ & $\begin{array}{l}\mathrm{M}_{\mathrm{w}} \text { after } \\
\text { deacylation }\end{array}$ & $\begin{array}{l}\text { Relative activity } \\
\text { per active sugar }\end{array}$ \\
\hline $4 a$ & 29200 & 30 & $\mathrm{n} / \mathrm{a}$ & 0 & 34400 & 28000 & $3820 \pm 1650$ \\
\hline $4 b$ & 26300 & 24 & 30200 & 7 & 33800 & 27600 & $2660 \pm 0$ \\
\hline $4 c$ & 22900 & 18 & 29700 & 13 & 34200 & 27700 & $2260 \pm 780$ \\
\hline 4d & 18700 & 10 & 33500 & 26 & 36100 & 30200 & $1090 \pm 380$ \\
\hline $4 e$ & $\mathrm{n} / \mathrm{a}$ & 0 & 28300 & 29 & 36300 & 28900 & $260 \pm 110$ \\
\hline $5 a$ & 48000 & 44 & $\mathrm{n} / \mathrm{a}$ & 0 & 63500 & 51500 & $4830 \pm 2090$ \\
\hline $5 b$ & 44500 & 38 & 51000 & 13 & 65500 & 51500 & $3040 \pm 0$ \\
\hline $5 c$ & 34700 & 16 & 57000 & 40 & 67000 & 56000 & $1270 \pm 440$ \\
\hline $5 d$ & $\mathrm{n} / \mathrm{a}$ & 0 & 49500 & 45 & 66000 & 54000 & $310 \pm 130$ \\
\hline $6 a$ & 77000 & 53 & $\mathrm{n} / \mathrm{a}$ & 0 & 113500 & 93000 & $5350 \pm 0$ \\
\hline $6 b$ & 68000 & 34 & 86500 & 35 & 115500 & 95500 & $3510 \pm 1220$ \\
\hline $6 c$ & 58500 & 16 & 85500 & 50 & 115000 & 95500 & $2150 \pm 0$ \\
\hline $6 d$ & $\mathrm{n} / \mathrm{a}$ & 0 & 90000 & 77 & 116000 & 94500 & $470 \pm 0$ \\
\hline
\end{tabular}

${ }^{\mathrm{a}}$ \# sugar residues was determined using MALDI-TOF MS data after deacetylation $\left(\mathrm{M}_{\mathrm{W}}=168 \mathrm{~g} / \mathrm{mol}\right.$ for 4 Ac) and after addition of tethered sugar $\left(\mathrm{M}_{\mathrm{W}}=507 \mathrm{~g} / \mathrm{mol}\right.$ per tethered sugar $) .{ }^{\mathrm{b}}$ Active sugar = mannose + glucose. Standard deviation values are very large because of serial 2 fold dilutions. For standard deviation $=0$, all inhibitory concentrations were equal. All values represent at least three trials. 
Values for equation 1: $\mathrm{K}_{\mathrm{N}}{ }^{\text {poly }}=\left(\mathrm{K}^{\text {mono }}\right)^{\square \mathrm{N}}$ was presented by Whitesides and co-workers (reference 3 of the main paper: Mammen, M.; Choi, S. K.; Whitesides, G. M.; Angew. Chem, Int. $E d$. 1998, 37, 2754-2794). $\mathrm{K}^{\text {mono }}$ is the monovalent association constant, $\mathrm{K}_{\mathrm{N}}{ }^{\text {poly }}$ is the multivalent association constant, $\mathrm{N}$ is the number of receptor-ligand interactions, and $\square$ is the cooperativity factor. Negatively cooperative, positively cooperative, and non-cooperative systems are all theoretically possible. However, only one or two examples of protein-carbohydrate interactions with thermodynamic parameters suggestive of positive cooperativity have been reported (see references 3 and 4 of the main paper). Negatively cooperative and non-cooperative systems are much more common. We've chosen to leave $\square=1$ because of precedent where non-cooperative associations were assumed for Con A (Corbell, J. B.; Lundquist, J. J.; Toone, E. J. Tetrahedron Asymm. 2000, 11, 95-111) and because a Con A-dendrimer interaction where the first binding event at one binding site is thermodynamically significantly different from the second binding event at a second binding site. Although it is possible that $\square \neq 1$, the values of cooperativity for glucose and mannose-functionalized dendrimers are surely comparable, causing any errors due to an incorrect assumption regarding cooperativity to cancel. Although the appropriate value of $\mathrm{N}$ for this system cannot be assigned with absolute certainty (because precipitation occurs under conditions appropriate for ITC), $\mathrm{N}$ must surely be equal to one or two. The shape of tetrameric Con $\mathrm{A}$ and the relative locations of the mannose binding sites on tetrameric Con A preclude trivalent or tetravalent binding by a roughly spherical, dendritic system. Although a value of $\mathrm{N}=$ 1 is possible, $\mathrm{N}=2$ is suggested by the results of previously published precipitation assay experiments, transmission electron micrographs, and hemagglutination assays (see reference 9 of the main paper and Woller, E. K.; Cloninger, M. J. Org. Lett. 2002, 4, 7-10).

\section{General hemagglutination assay procedures}

\section{Concanavalin A preparation.}

In a $10 \mathrm{~mL}$ centrifuge tube, approximately $5 \mathrm{mg}$ of Concanavalin A (Con A) was dissolved without agitation in $10 \mathrm{~mL}$ of HEPES buffer with $100 \square \mathrm{M} \mathrm{CaCl}_{2}(\mathrm{pH}=8.5)$. The tube was stored at $4{ }^{\circ} \mathrm{C}$ for 8 hours to allow the Con A to dissolve. Afterwards, the solution was placed in a dialysis tube and dialyzed against $1 \mathrm{~L}$ of tris buffered saline (TBS) for 4 hours. This was repeated with fresh TBS solution, followed by dialysis against $1 \mathrm{~L}$ of phosphate-buffered saline (PBS) for 8 hours. The dialysis was done to remove any excess $\mathrm{Ca}^{2+}$ from the lectin solution. The Con $\mathrm{A}$ solution was removed from the tube and stored at $4{ }^{\circ} \mathrm{C}$ until needed.

\section{Blood preparation.}

Fresh whole rabbit blood was obtained from the MSU animal care center in 4mL vials. Alsever's solution was added to the blood to make up a 60:40 v/v solution. The blood was separated into 2 $\mathrm{mL}$ aliquots in $15 \mathrm{~mL}$ centrifuge tubes. These were then diluted to $12 \mathrm{~mL}$ with Alsevers solution. The cells were pelleted by centrifugation $(1100 \mathrm{rpm} \times 10 \mathrm{~min})$, and the layer of white blood cells and plasma proteins was removed by pipette. This process was repeated 2 more times using PBS instead of Alsever's solution. The blood was then made up in the assay buffer solution, PBS w/ $0.5 \%$ BSA. Hemagglutination assays were all performed on blood obtained from the same rabbit on the same day. Although trends remain constant, values obtained from the hemagglutination assay change when blood samples from different rabbits are used or when blood from the same rabbit is drawn at different times. 


\section{Concanavalin A titration}

Decreasing amounts of Con A were incubated with red blood cells to determine the lectin concentration needed to agglutinate the cells. Serial two fold dilutions were made in the wells of a 96 well V-bottomed microtiter plate. The two fold dilutions were made by adding $50 \square \mathrm{L}$ of Con A solution to the first well, then $50 \square \mathrm{L}$ of buffer solution to the all 24 wells. $50 \square \mathrm{L}$ was then transferred from the first well to the second. The second well was mixed and $50 \square \mathrm{L}$ was transferred to the third well. This procedure was repeated until the $24^{\text {th }}$ well two fold serial dilutions through all wells of interest. To each well $50 \square \mathrm{L}$ of the blood solution was added and incubated for 2 hours at $22-25{ }^{\circ} \mathrm{C}$. after this time the wells were examined and the amount of con A required to agglutinate the cell suspension was determined. This was then considered to be 1 unit. For the inhibition assay an 8 unit Con A solution was made up, and the concentration of con A determined by spectrophotometric analysis.

\section{Inhibiting Dose determination}

Starting with a concentration of $5 \mathrm{mg} / \mathrm{mL}$ serial two-fold dilutions of the inhibitor's were made as described above. The inhibitor solutions were incubated with $50 \square \mathrm{L}$ of the 8 unit Con $\mathrm{A}$ solution for $2-3$ hours at $22-25{ }^{\circ} \mathrm{C}$. After this time $50 \square \mathrm{L}$ of the blood solution was added and the wells were mixed and incubated for 2 hours at $22-25^{\circ} \mathrm{C}$. The minimum concentration causing inhibition was determined and this was the inhibiting dose. 
Figure S1. ${ }^{1} \mathrm{H}$ NMR spectrum $\left(500 \mathrm{MHz}, \mathrm{CDCl}_{3}\right)$ of $\mathbf{1 b}$.

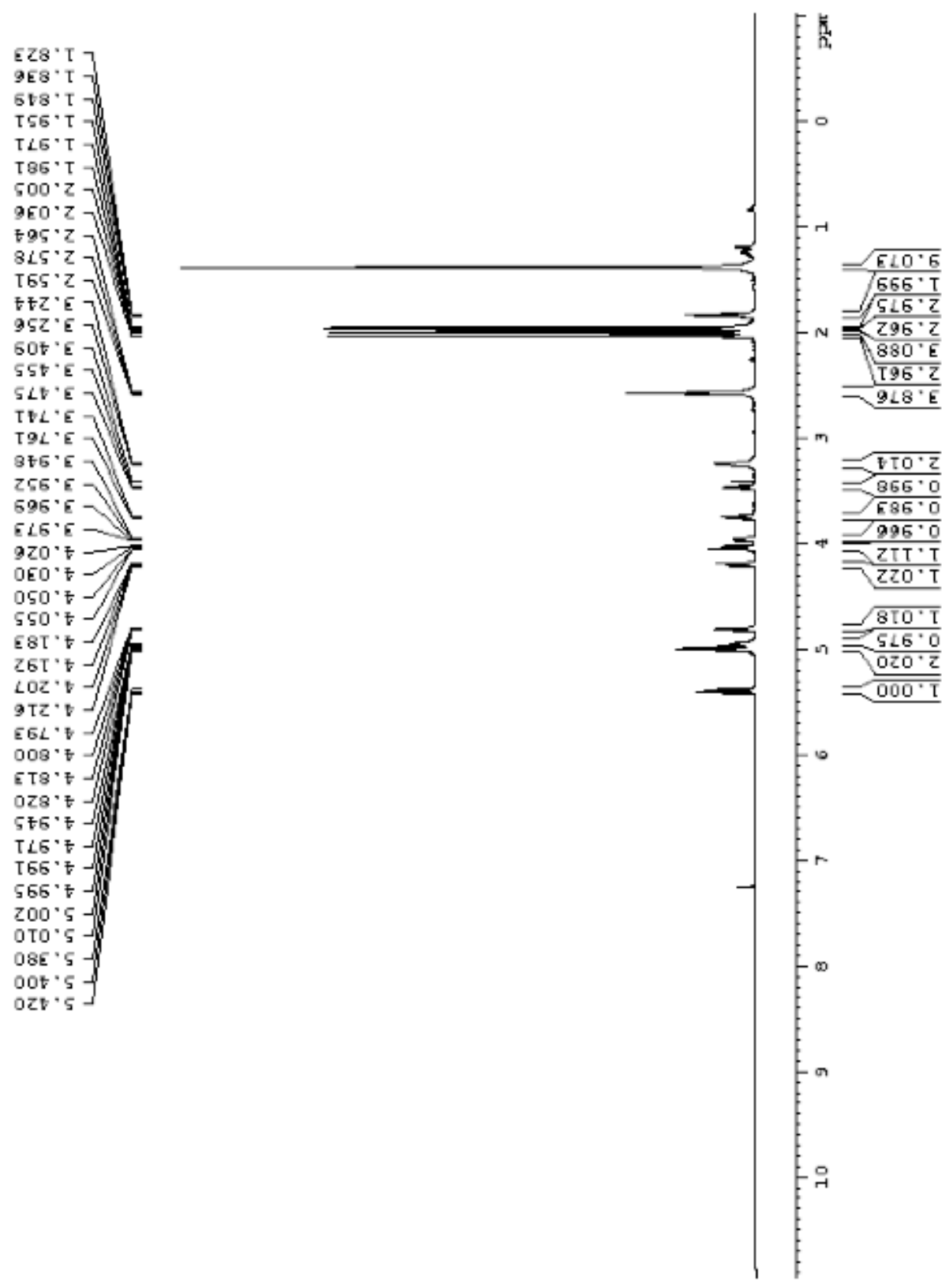


Figure S2. ${ }^{1} \mathrm{H} \mathrm{NMR}$ spectrum $\left(500 \mathrm{MHz}, \mathrm{CDCl}_{3}\right)$ of $\mathbf{2 a}$.

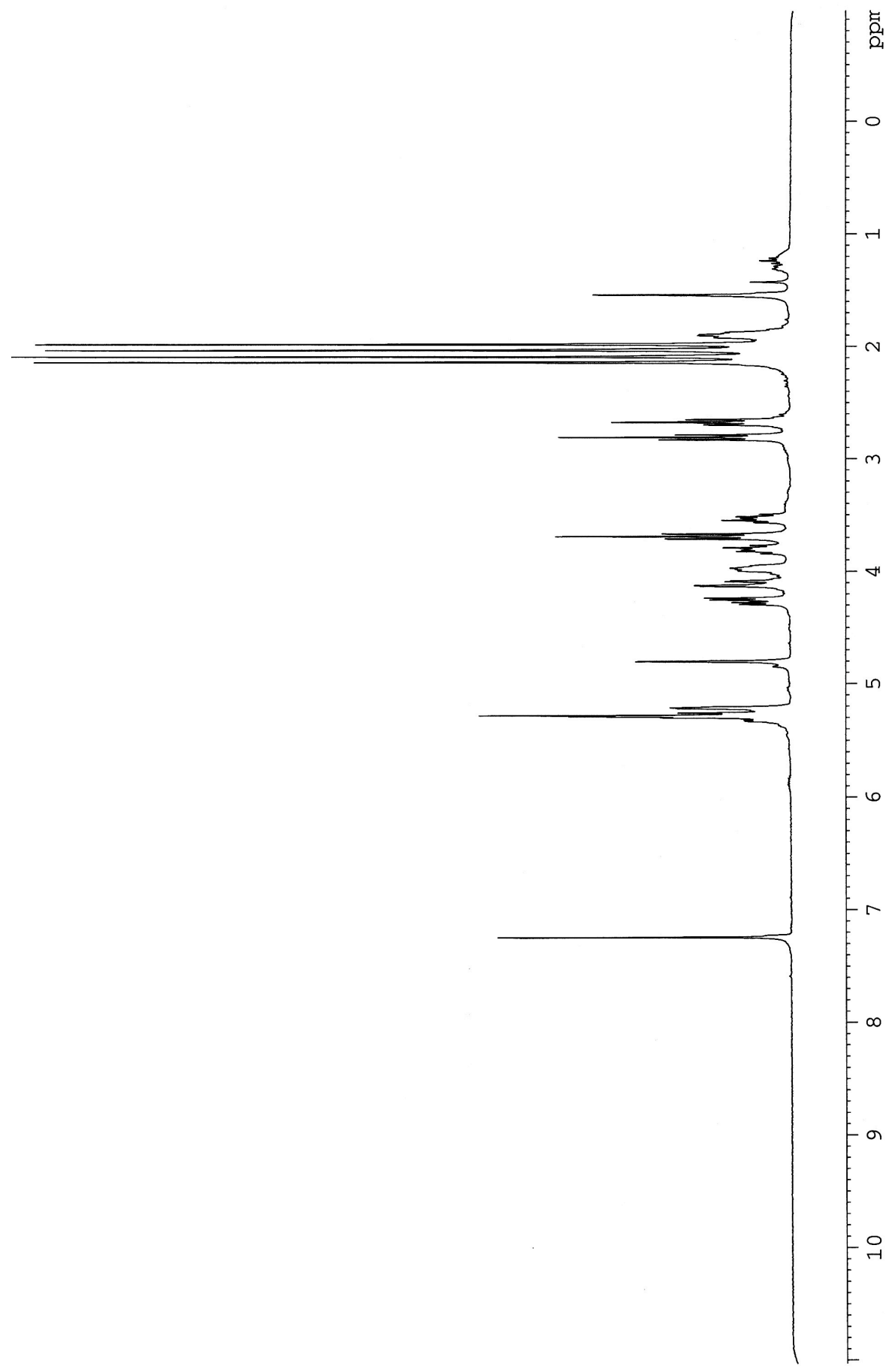


Figure S3. ${ }^{1} \mathrm{H}$ NMR spectrum $\left(500 \mathrm{MHz}, \mathrm{CDCl}_{3}\right)$ of $\mathbf{2 b}$.
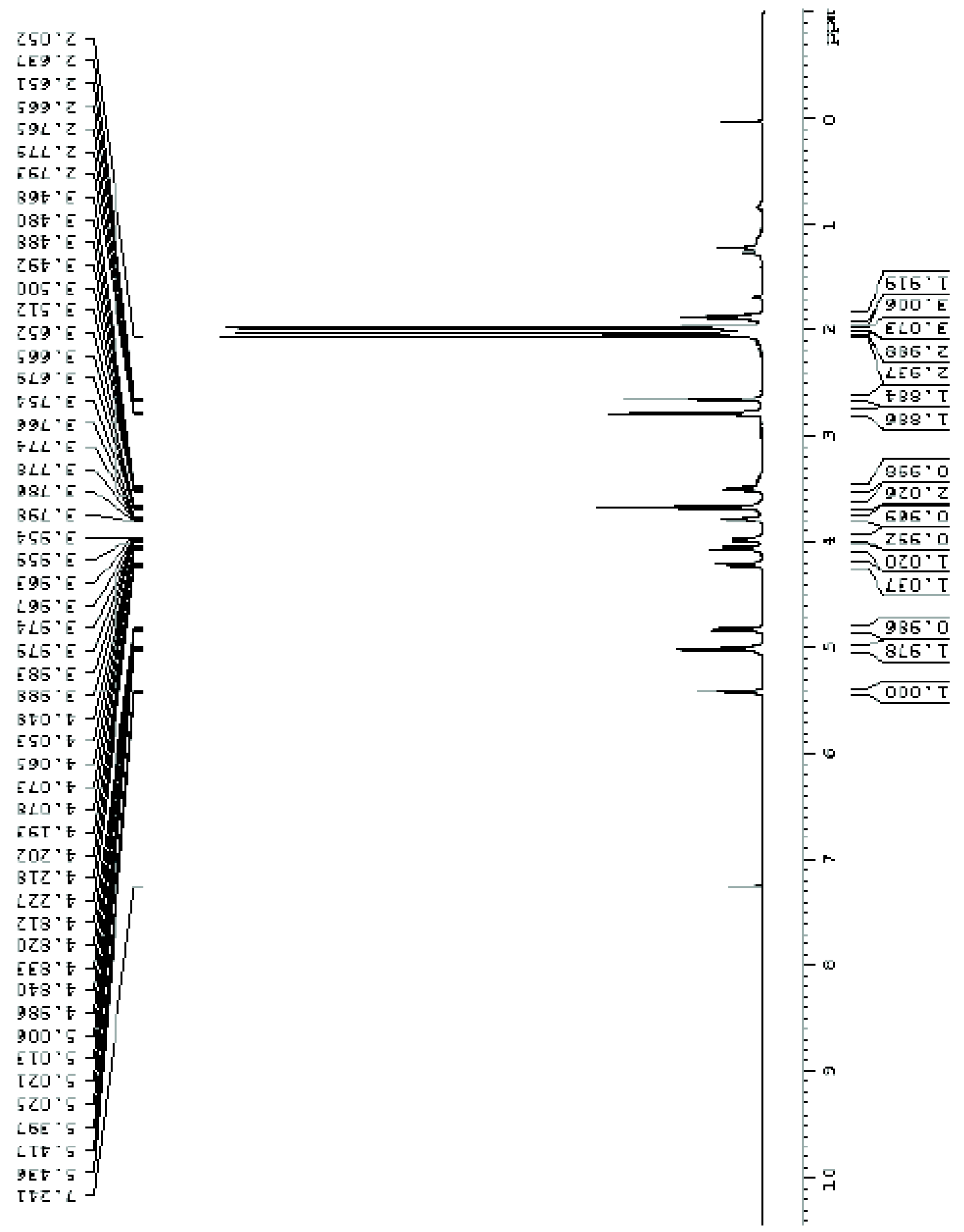
Figure S4. ${ }^{1} \mathrm{H}$ NMR spectrum $\left(500 \mathrm{MHz}, \mathrm{CDCl}_{3}\right)$ of $\mathbf{2 c}$.

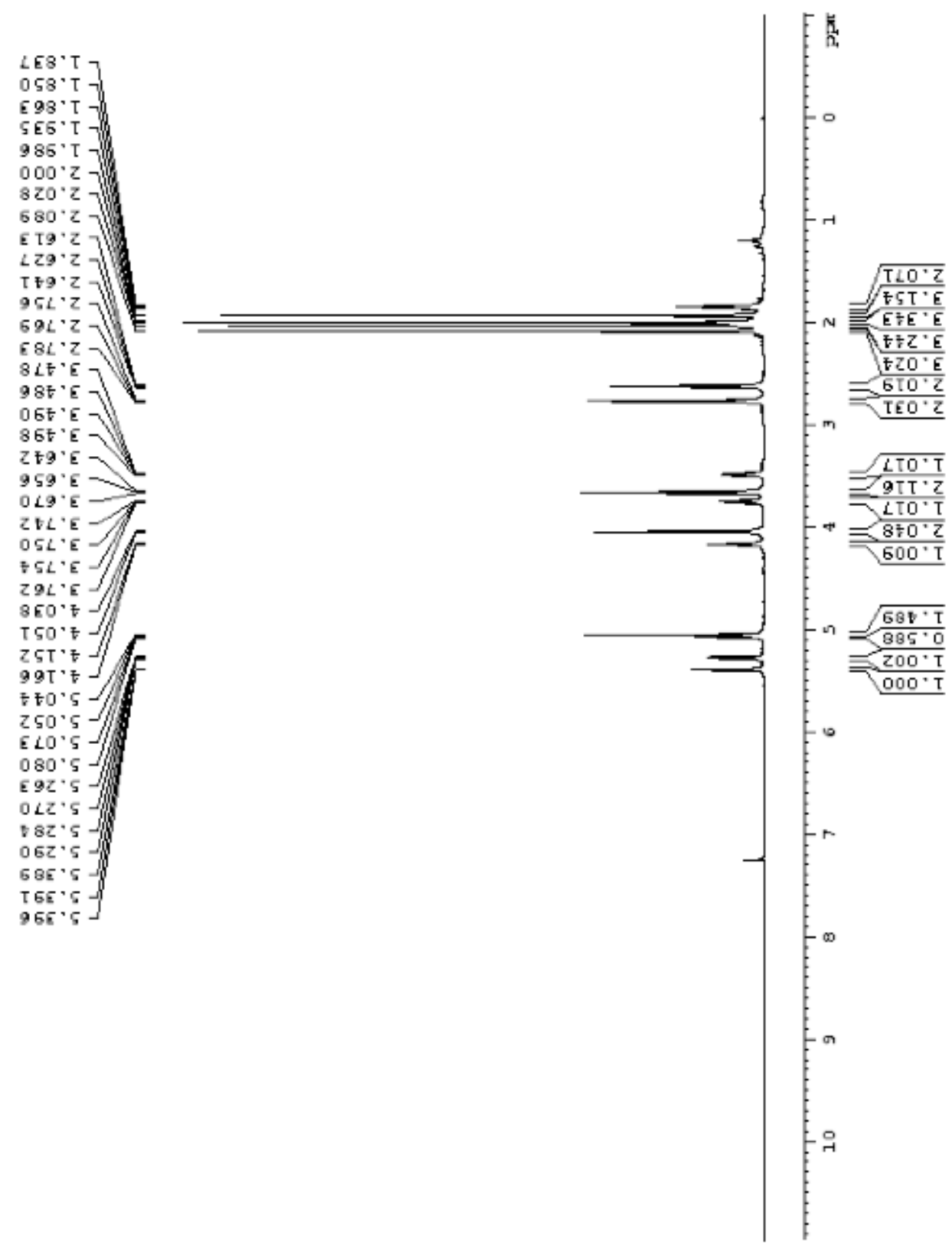


Figure S5. ${ }^{1} \mathrm{H}$ NMR spectra $\left(500 \mathrm{MHz}, \mathrm{CDCl}_{3}\right)$ of $\mathbf{2 a - c}$, expanded to highlight the sugar resonances. Top: $\mathbf{2 a}$, middle: $\mathbf{2 b}$, bottom: $\mathbf{2 c}$.

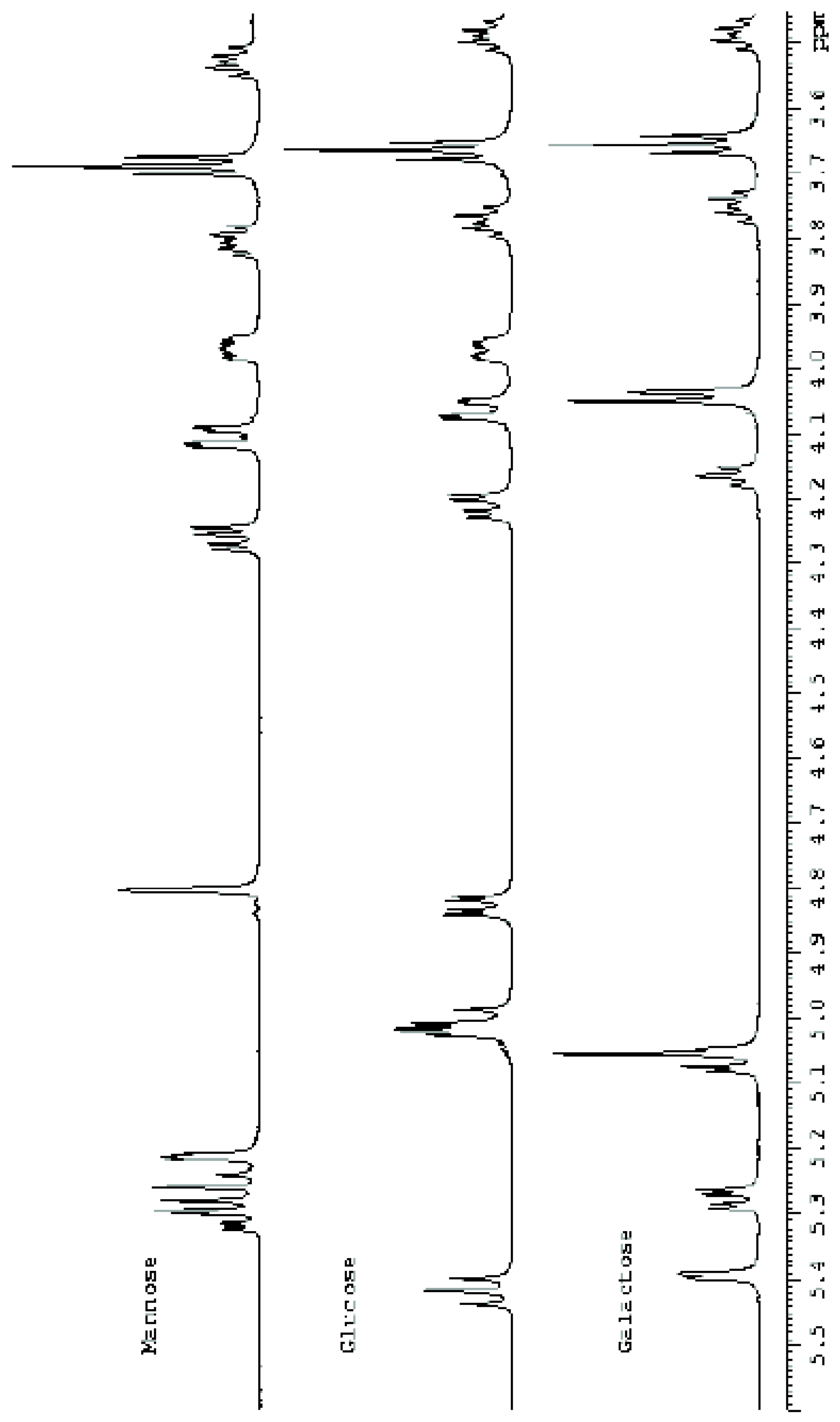


Figure S6. ${ }^{1} \mathrm{H}$ NMR spectrum (500 MHz, $d_{6}$-DMSO) of $\mathbf{4 c}$ (peracetylated).

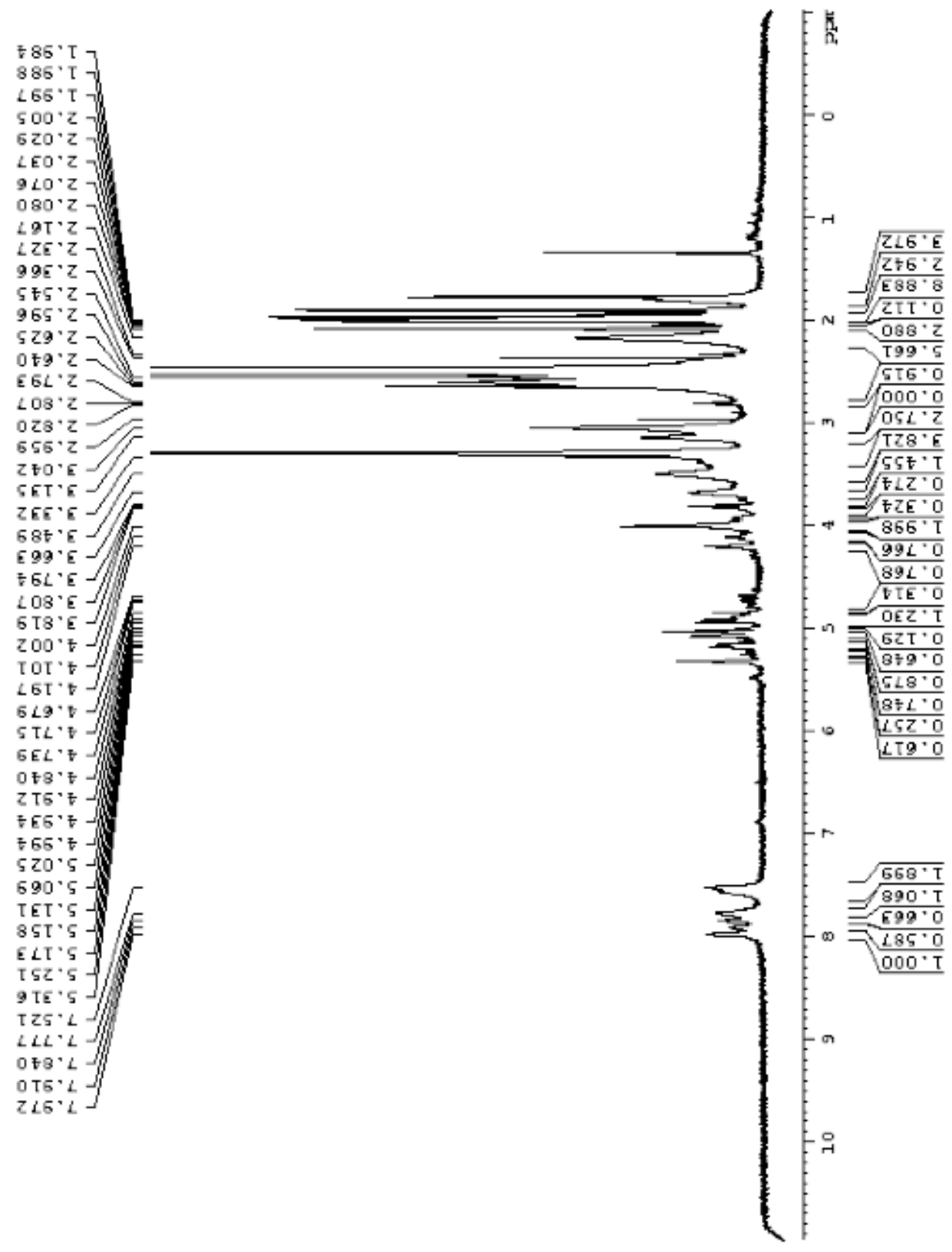


Figure S7. ${ }^{1} \mathrm{H}$ NMR spectrum $\left(500 \mathrm{MHz}, d_{6}\right.$-DMSO) of $4 \mathbf{c}$ (deacetylated).

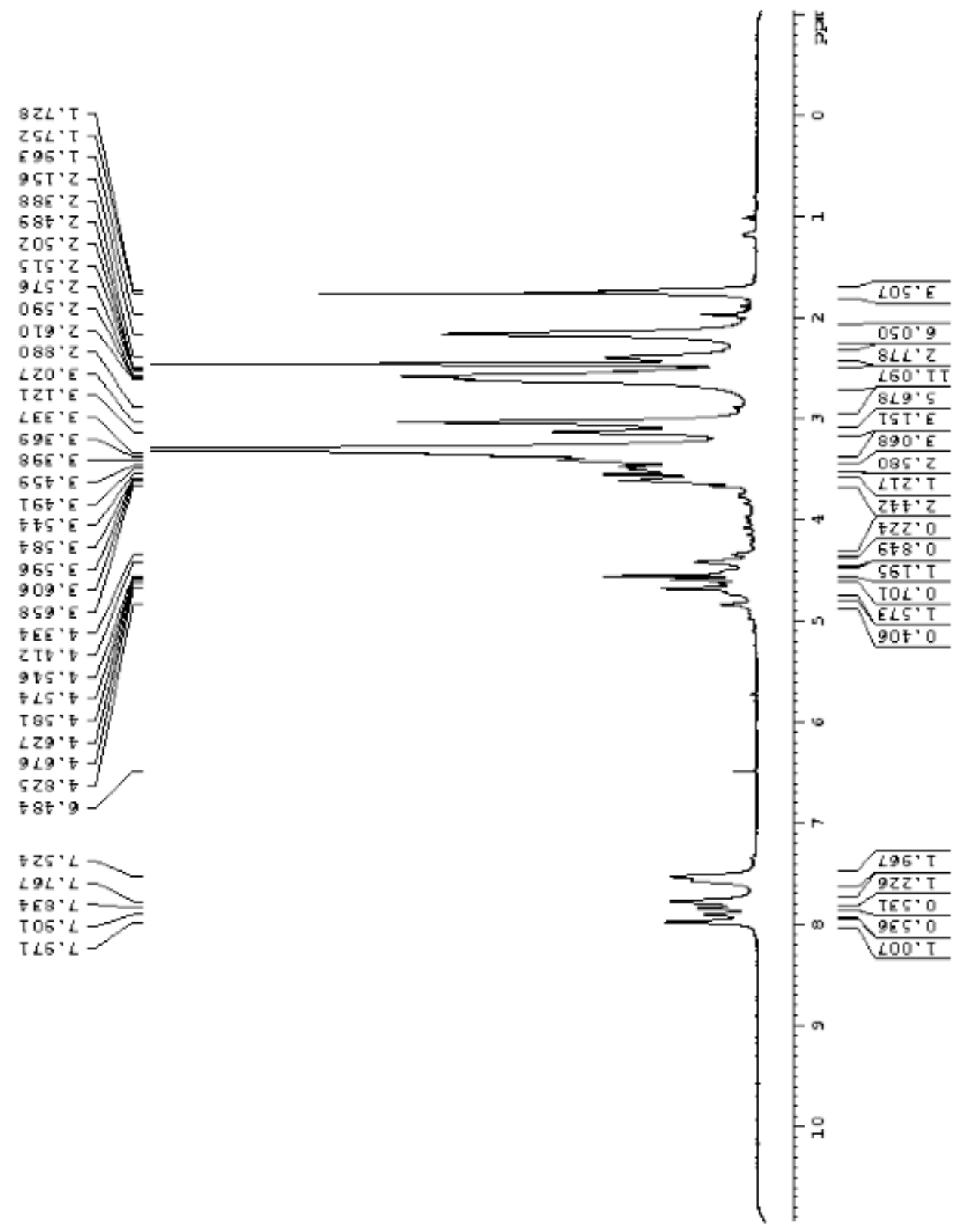


Figure S8. ${ }^{1} \mathrm{H}$ NMR spectrum ( $500 \mathrm{MHz}, d_{6}$-DMSO) of $\mathbf{5 e}$ (peracetylated).

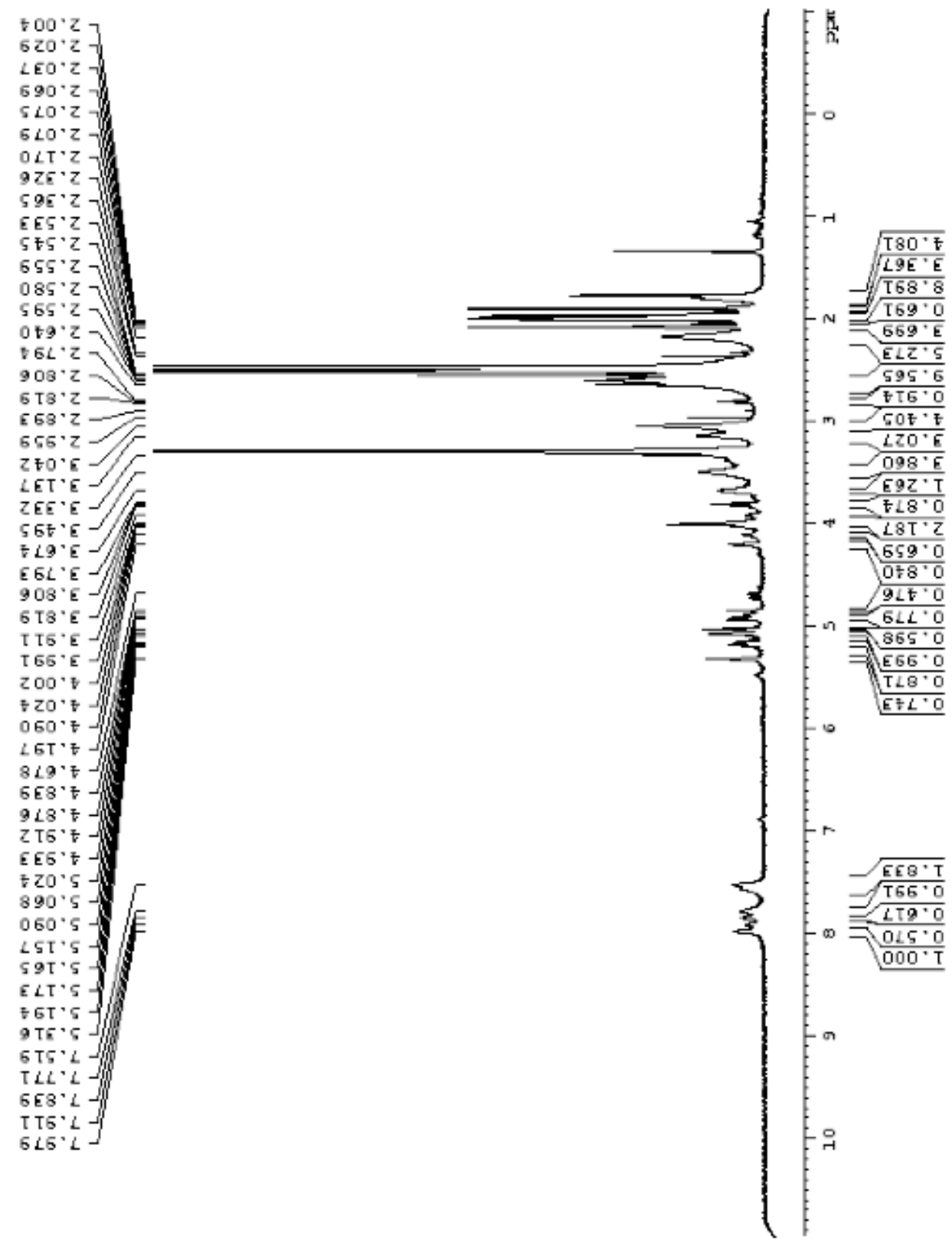


Figure S9. ${ }^{1} \mathrm{H}$ NMR spectrum $\left(500 \mathrm{MHz}, d_{6}\right.$-DMSO) of $\mathbf{5 e}$ (deacetylated).

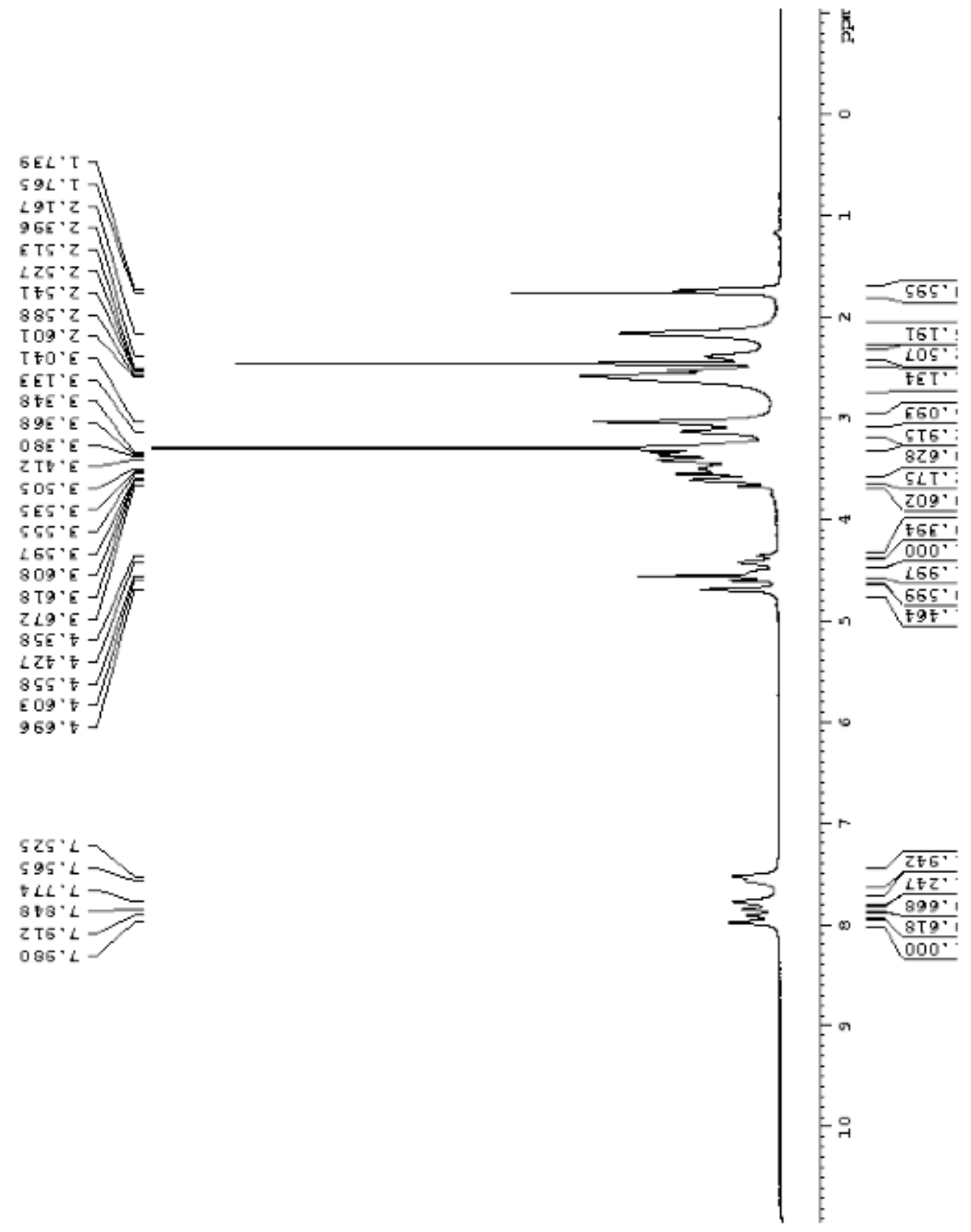


Figure S10. ${ }^{1} \mathrm{H}$ NMR spectrum $\left(500 \mathrm{MHz}, d_{6}\right.$-DMSO) of $\mathbf{6 d}$ (peracetylated).

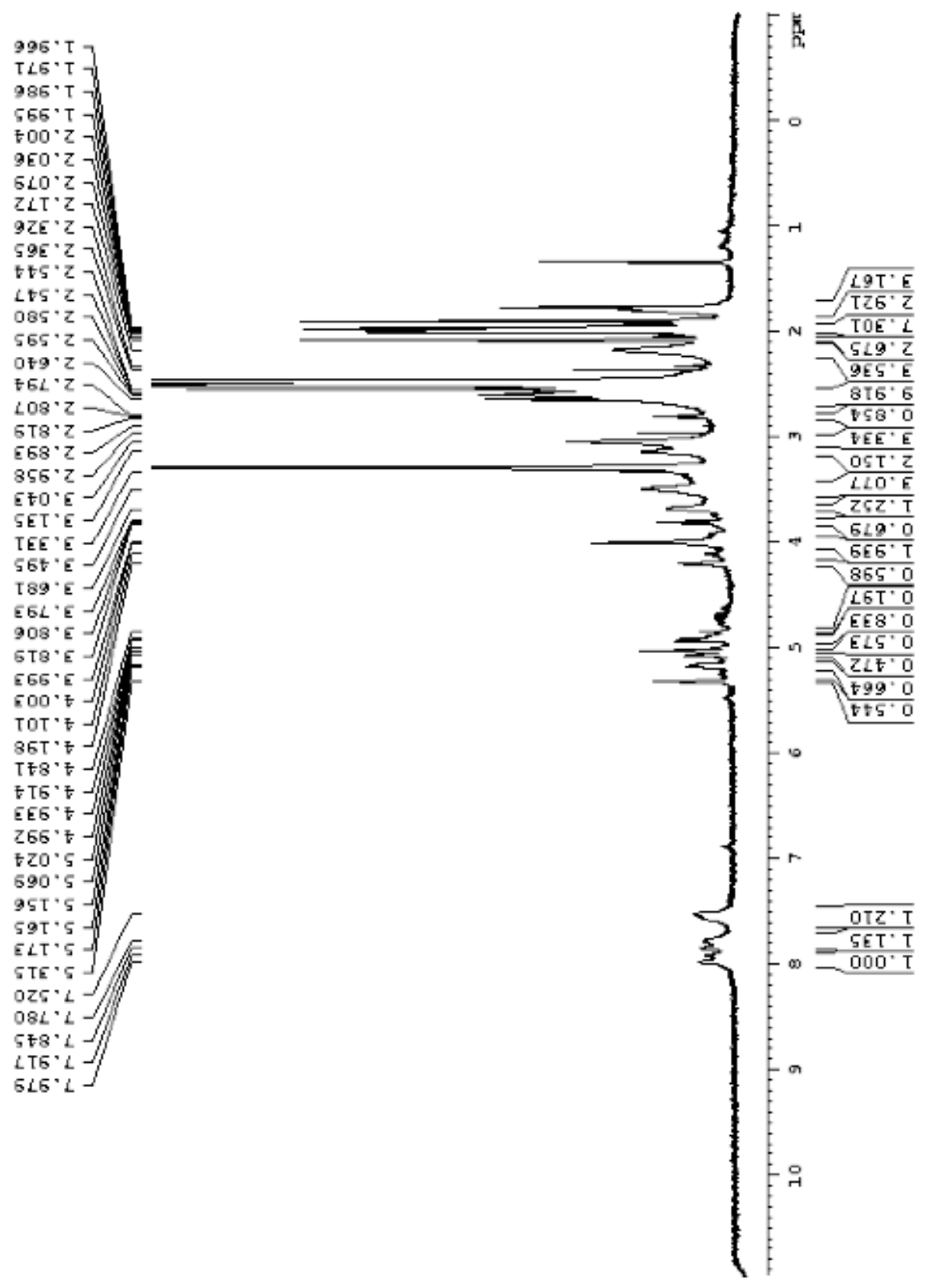


Figure S11. ${ }^{1} \mathrm{H}$ NMR spectrum (500 MHz, $d_{6}$-DMSO) of $\mathbf{6 d}$ (deacetylated).

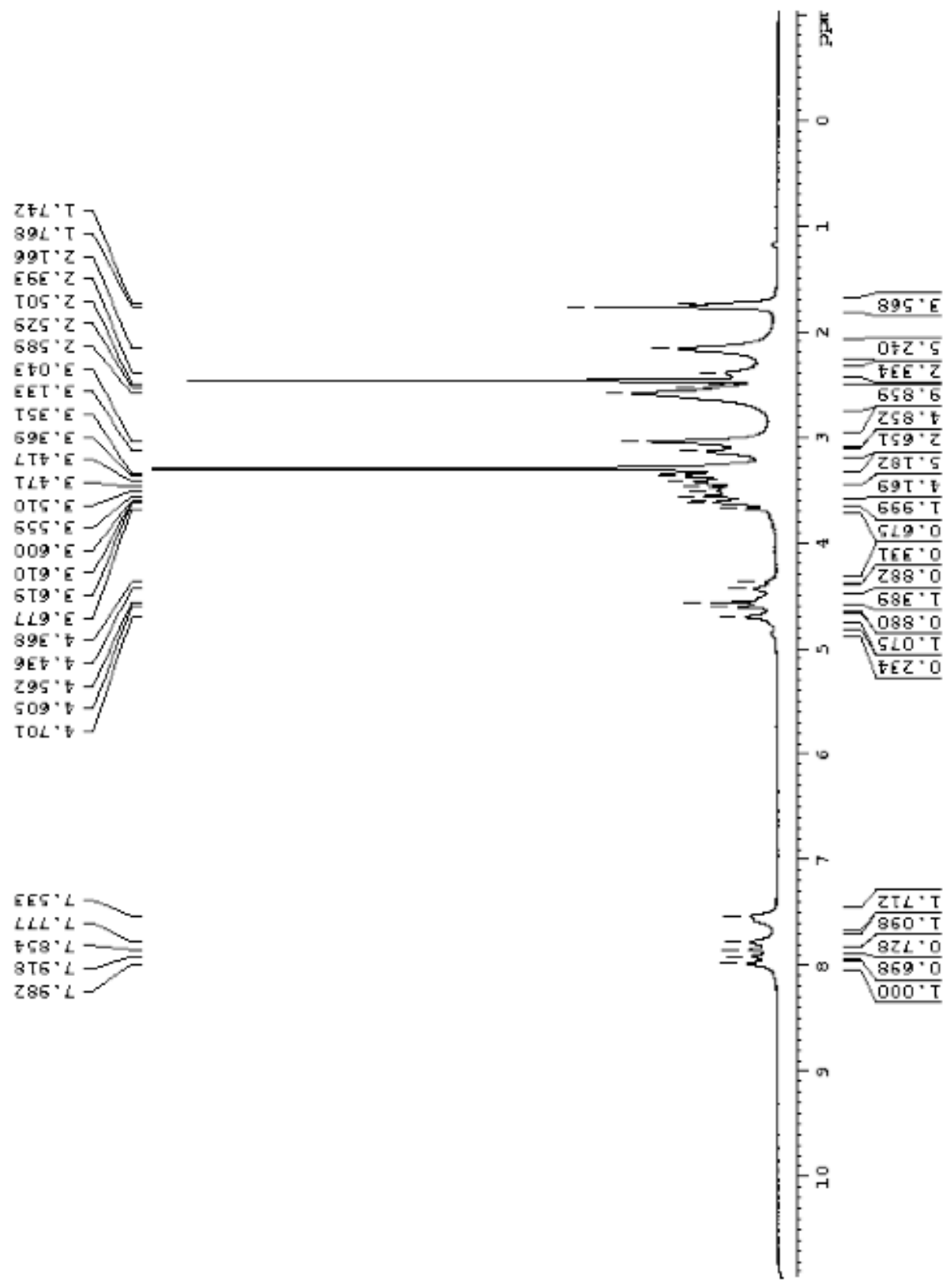


Figure S12. MALDI-TOF spectra of $4 \mathbf{c}$ peracetylated. $\mathrm{M}_{\mathrm{W}}=34200 \mathrm{~g} / \mathrm{mol}, \mathrm{PDI}=1.02$

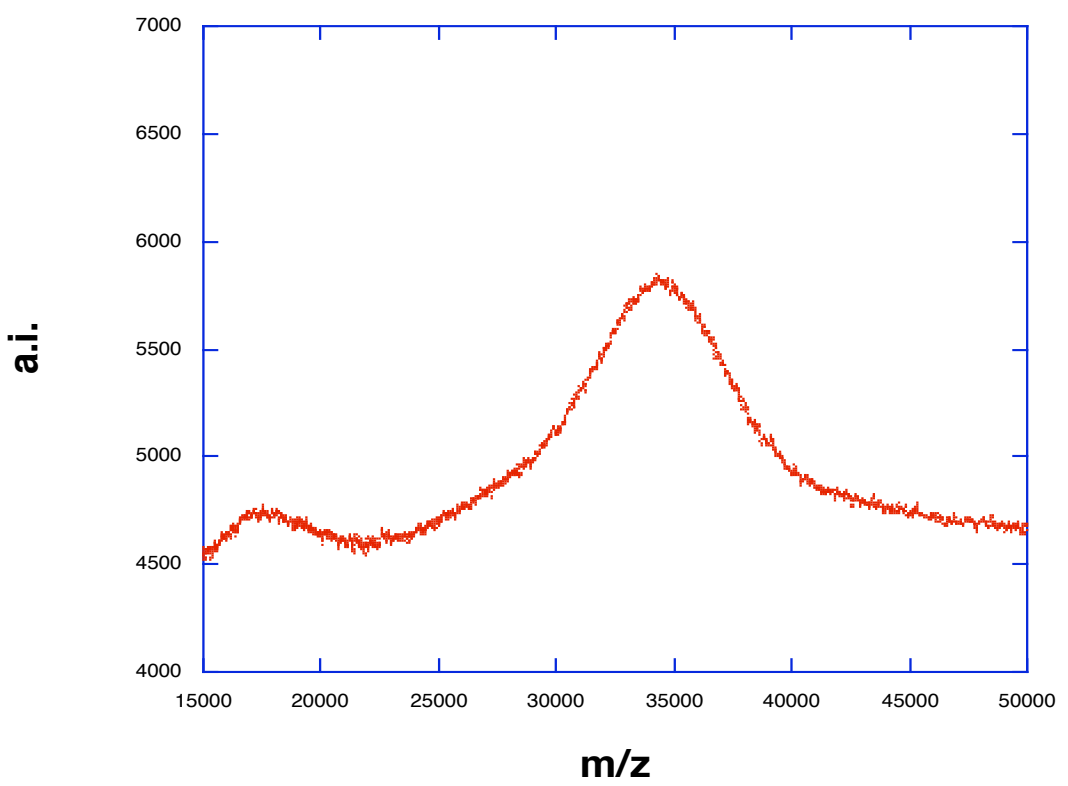

Figure S13. MALDI-TOF spectra of $4 \mathbf{c}$ deacylated, $\mathrm{M}_{\mathrm{W}}=27700 \mathrm{~g} / \mathrm{mol}, \mathrm{PDI}=1.01$.

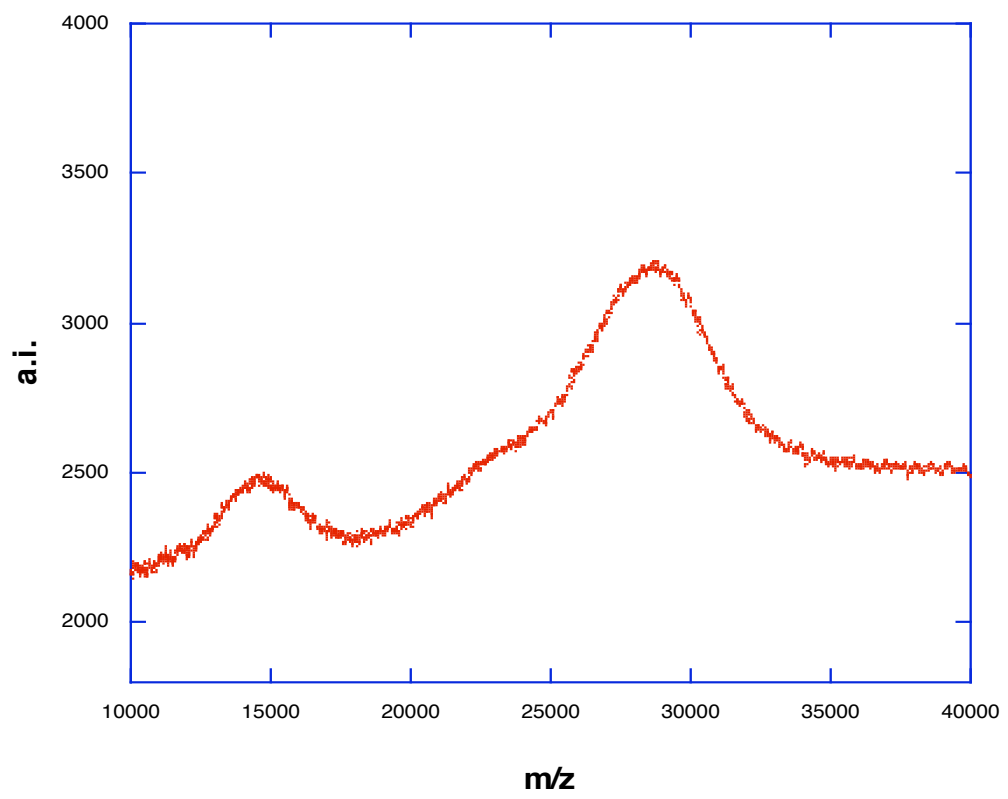


Figure S14. MALDI-TOF spectra of 5d peracylated. $\mathrm{M}_{\mathrm{W}}=63500 \mathrm{~g} / \mathrm{mol}, \mathrm{PDI}=1.02$.

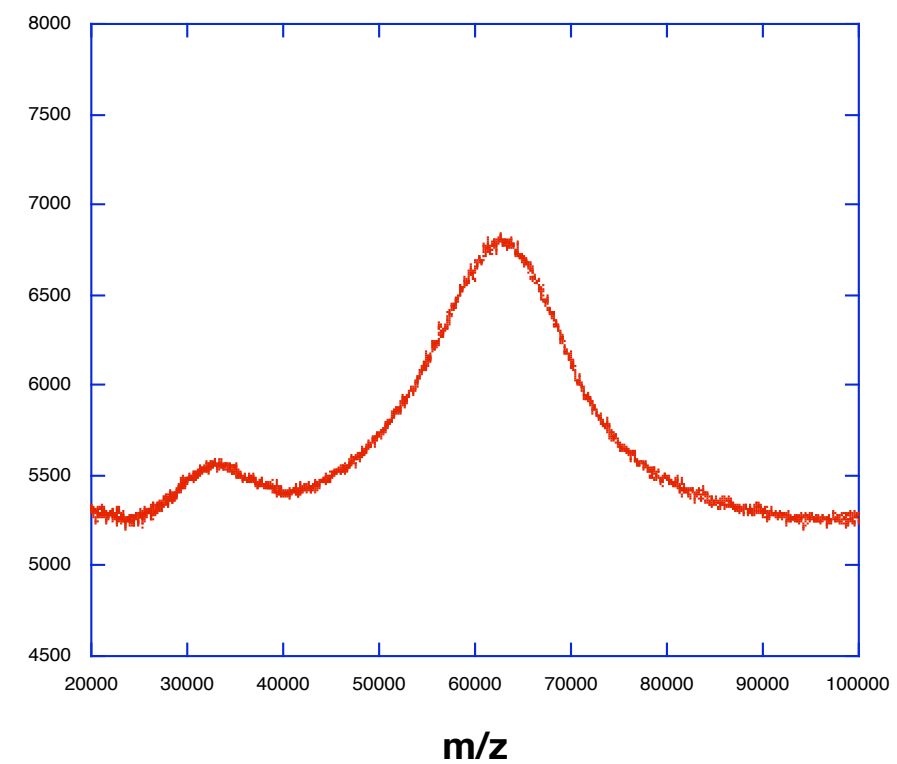

Figure S15. MALDI-TOF spectra of 5d deacylated, $\mathrm{M}_{\mathrm{W}}=54000 \mathrm{~g} / \mathrm{mol}, \mathrm{PDI}=1.01$

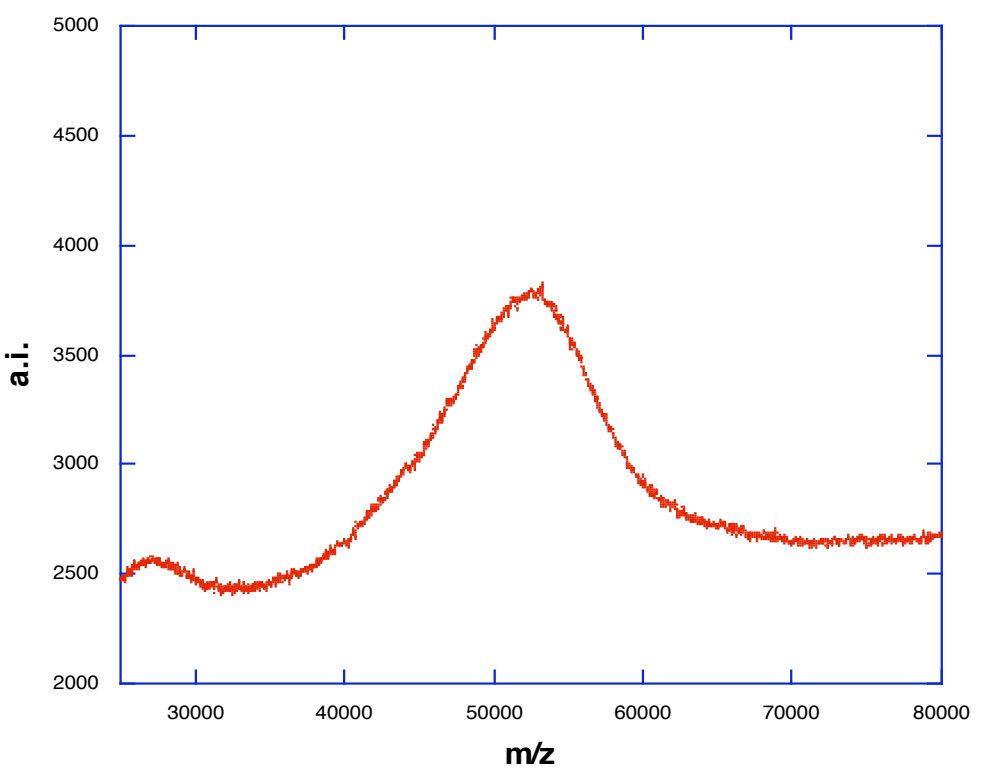


Figure S16. MALDI-TOF spectra of $6 \mathbf{c}$ peracylated. $\mathrm{M}_{\mathrm{W}}=115000, \mathrm{PDI}=1.02$

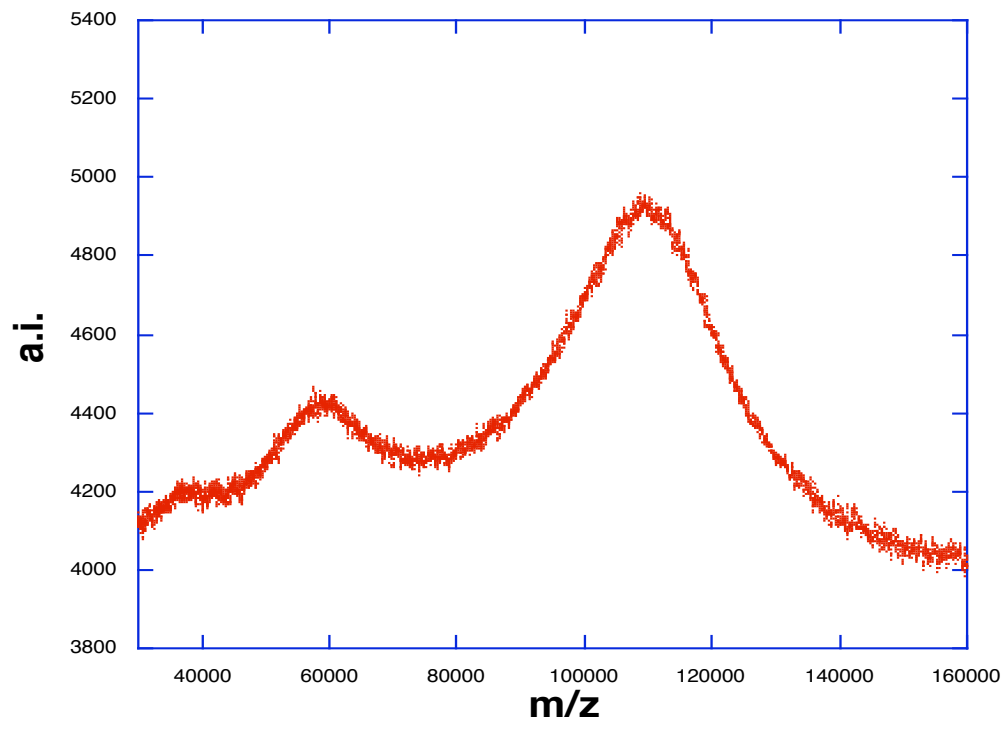

Figure S17. MALDI-TOF spectra of $6 \mathbf{c}$ deacylated, $\mathrm{M}_{\mathrm{W}}=94500 \mathrm{~g} / \mathrm{mol}, \mathrm{PDI}=1.01$

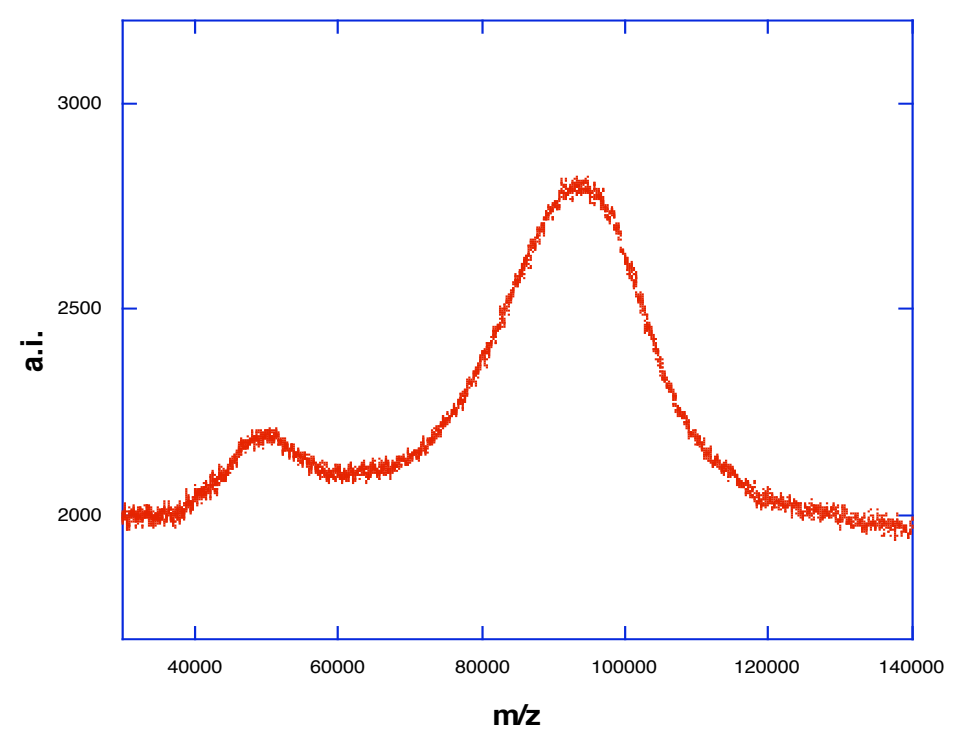

